\title{
Inherent calibration of a blue LED-CE-DOAS instrument to measure iodine oxide, glyoxal, methyl glyoxal, nitrogen dioxide, water vapour and aerosol extinction in open cavity mode
}

\author{
R. Thalman ${ }^{1}$ and R. Volkamer ${ }^{1,2}$ \\ ${ }^{1}$ Department of Chemistry and Biochemistry, University of Colorado, Boulder, CO, 80309, USA \\ ${ }^{2}$ Cooperative Institute for Research in Environmental Sciences (CIRES), Boulder, CO, 80309, USA
}

Received: 1 May 2010 - Published in Atmos. Meas. Tech. Discuss.: 24 June 2010

Revised: 3 December 2010 - Accepted: 13 December 2010 - Published: 22 December 2010

\begin{abstract}
The combination of Cavity Enhanced Absorption Spectroscopy (CEAS) with broad-band light sources (e.g. Light-Emitting Diodes, LEDs) lends itself to the application of cavity enhanced Differential Optical Absorption Spectroscopy (CE-DOAS) to perform sensitive and selective point measurements of multiple trace gases and aerosol extinction with a single instrument. In contrast to other broad-band CEAS techniques, CE-DOAS relies only on the measurement of relative intensity changes, i.e. does not require knowledge of the light intensity in the absence of trace gases and aerosols $\left(I_{0}\right)$. We have built a prototype LED-CE-DOAS instrument in the blue spectral range (420$490 \mathrm{~nm})$ to measure nitrogen dioxide $\left(\mathrm{NO}_{2}\right)$, glyoxal (CHO$\mathrm{CHO}$ ), methyl glyoxal $\left(\mathrm{CH}_{3} \mathrm{COCHO}\right)$, iodine oxide (IO), water vapour $\left(\mathrm{H}_{2} \mathrm{O}\right)$ and oxygen dimers $\left(\mathrm{O}_{4}\right)$. We demonstrate the first direct detection of methyl glyoxal, and the first CE-DOAS detection of CHOCHO and IO. The instrument is further inherently calibrated for light extinction from the cavity by observing $\mathrm{O}_{4}$ or $\mathrm{H}_{2} \mathrm{O}$ (at $477 \mathrm{~nm}$ and $443 \mathrm{~nm}$ ) and measuring the pressure, relative humidity and temperature independently. This approach is demonstrated by experiments where laboratory aerosols of known size and refractive index were generated and their extinction measured. The measured extinctions were then compared to the theoretical extinctions calculated using Mie theory $\left(3-7 \times 10^{-7} \mathrm{~cm}^{-1}\right)$. Excellent agreement is found from both the $\mathrm{O}_{4}$ and $\mathrm{H}_{2} \mathrm{O}$ retrievals. This enables the first inherently calibrated CEAS measurement at blue wavelengths in open cavity mode, and eliminates the need for sampling lines to supply air to the cavity, i.e., keep the cavity enclosed and/or aerosol free.
\end{abstract}

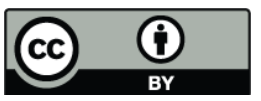

Correspondence to: R. Volkamer (rainer.volkamer@colorado.edu)
Measurements in open cavity mode are demonstrated for $\mathrm{CHOCHO}, \mathrm{CH}_{3} \mathrm{COCHO}, \mathrm{NO}_{2}, \mathrm{H}_{2} \mathrm{O}$ and aerosol extinction. Our prototype LED-CE-DOAS provides a low cost, yet research grade innovative instrument for applications in simulation chambers and in the open atmosphere.

\section{Introduction}

Light-Emitting Diode (LED) light sources coupled with Cavity Enhanced Absorption Spectroscopy (CEAS) and Differential Optical Absorption Spectroscopy (DOAS) retrievals hold great potential for a light-weight, low-power and portable instrument to enable the sensitive and selective measurement of numerous atmospheric trace gases and aerosol extinction with a single instrument. In the last ten years several high-finesse cavity techniques have expanded on the principles of Cavity Ring-Down Spectroscopy (CRDS) (O'Keefe and Deacon, 1988; Brown, 2003). CRDS, CEAS, and integrated cavity output spectroscopy (ICOS) have in common the use of a high-finesse optical cavity consisting of two highly reflective mirrors to increase the absorption path length over that of conventional White-type (White, 1942), Herriott-type (Herriott and Schulte, 1965) or astigmatic (McManus et al., 1995) multi-reflection cells by several orders of magnitude. The long path length leads to greatly increased sensitivities of these techniques. CEAS works on many of the same principles as CRDS, but can be coupled with broad band (non-laser) light sources, either in the form of thermal emitters (Incoherent Broadband CEAS) or LEDs (LED-CEAS). CEAS techniques have been used to measure a wide variety of atmospheric trace gases including: nitrogen dioxide $\left(\mathrm{NO}_{2}\right)$ (Ball et al., 2004; Venables et al., 2006;

Published by Copernicus Publications on behalf of the European Geosciences Union. 
Table 1. Previous CEAS instruments in the blue spectral range.

\begin{tabular}{llrll}
\hline Light Source & Mirror Reflectivity & $\begin{array}{r}\text { Useable Spectral } \\
\text { Range }(\mathrm{nm})\end{array}$ & Detected Species & Reference \\
\hline Xe Arc & 1.0 .999 & $1.415-450$ & $\mathrm{IO}$ & Vaughan et al. (2008) \\
& 2.0 .9998 & $2.427-450$ & $\mathrm{IO}$ & \\
Xe Arc & 0.999967 & $440-465$ & $\mathrm{CHOCHO}_{2} \mathrm{NO}_{2}, \mathrm{H}_{2} \mathrm{O}$ & Washenfelder et al. (2008) \\
LED & 0.99976 & $440-460$ & $\mathrm{NO}_{2}, \mathrm{O}_{4}^{\mathrm{a}}$ & Langridge et al. (2006) \\
LED & 0.9997 & $420-480$ & $\mathrm{NO}_{2}, \mathrm{O}_{4}^{\mathrm{a}}$ & Ball and Jones (2009) \\
LED & 0.997 & $450-490$ & $\mathrm{NO}_{2}, \mathrm{O}_{4}^{\mathrm{b}}$ & Wu et al. (2009) \\
LED & 0.999964 & $420-490$ & $\mathrm{CHOCHO}_{3} \mathrm{CH}_{3} \mathrm{COCHO}, \mathrm{IO}, \mathrm{NO}_{2}, \mathrm{O}_{4}^{\mathrm{c}}, \mathrm{H}_{2} \mathrm{O}$ & This work \\
\hline
\end{tabular}

${ }^{\text {a }}$ In pure $\mathrm{O}_{2}$ at 446 (25 times enhancement of $\mathrm{O}_{4}$ over ambient conditions).

${ }^{\mathrm{b}}$ In pure $\mathrm{O}_{2}$ at $477 \mathrm{~nm}$.

${ }^{\mathrm{c}}$ In ambient air at 446 and $477 \mathrm{~nm}$.

Langridge et al., 2006, 2008a,b; Gherman et al., 2008; Triki et al., 2008; Washenfelder et al., 2008; Wu et al., 2009), the nitrate radical $\left(\mathrm{NO}_{3}\right)$ (Ball et al., 2004; Venables et al., 2006; Langridge et al., 2006, 2008a,b; Gherman et al., 2008; Meinen et al., 2008; Triki et al., 2008; Schuster et al., 2009), dinitrogen pentoxide $\left(\mathrm{N}_{2} \mathrm{O}_{5}\right)$ (Schuster et al., 2009), nitrous acid (HONO) (Gherman et al., 2008), water vapor $\left(\mathrm{H}_{2} \mathrm{O}\right)$ (Venables et al., 2006; Langridge et al., 2008a,b; Washenfelder et al., 2008), ozone $\left(\mathrm{O}_{3}\right)$ (Venables et al., 2006; Chen and Venables, 2010), oxygen dimer $\left(\mathrm{O}_{4}\right)$ (Langridge et al., 2006; Chen and Venables, 2010), iodine $\left(\mathrm{I}_{2}\right)$ (Ball et al., 2004; Vaughan et al., 2008; Dixneuf et al., 2009), iodine monoxide (IO) (Vaughan et al., 2008), iodine dioxide (OIO) (Vaughan et al., 2008), bromine oxide (BrO), sulfur dioxide $\left(\mathrm{SO}_{2}\right)$ (Chen and Venables, 2010), and glyoxal (CHOCHO) (Washenfelder et al., 2008). CEAS techniques have also been used to measure the rather "broad band" absorption cross section spectra of acetone, 2-butanone, and 2pentanone (Chen and Venables, 2010). Available CEAS instruments to measure atmospheric trace gases in the blue spectral range $(420-490 \mathrm{~nm})$ are shown in Table 1. These techniques have incorporated both Xe-arc lamps and LEDs as light sources.

Traditional CEAS techniques rely on absolute intensity measurements to determine trace gas extinctions (Fiedler et al., 2003). Such measurements are susceptible to lamp drifts. Additionally, the ability of existing CEAS techniques to separate and quantify the temporal variability of extinction losses due to aerosols, turbulence, and changes in the mirror reflectivity and/or cavity alignment from the trace gases of interest remains poorly developed. CEAS measurements to date require frequent calibration measurements, which are time consuming and reduce the duty cycle of measurements. Further, the temporal variability of aerosol extinction in the atmosphere poses a major challenge to measurements in open cavity mode, and aerosols often need to be removed from the cavity by means of filtration in sampling lines to enable quantitative measurements. Cavity Enhanced Differential Optical Absorption Spectroscopy (CE-DOAS) is a novel CEAS technique under development (Meinen et al., 2008; Platt et al., 2009). CE-DOAS in principle holds promise to retrieve both aerosol and trace gas information simultaneously, but this potential had as of yet not been systematically exploited. CE-DOAS and other CEAS techniques have in common the use of a high finesse optical cavity coupled to a broad band light source; broad areas of the spectrum (several $10 \mathrm{~nm}$ ) are simultaneously measured by means of a single detector (multiplexing advantage). DOAS retrievals are inherently insensitive to variations in the absolute light intensity (Platt and Stutz, 2008), as DOAS relies on measuring narrow band ( $<3-5 \mathrm{~nm}$ FWHM) "differential" absorption features of trace gases; the differential absorption is independent of intensity variations, i.e., does not require knowledge of the light intensity in the absence of absorbers, $I_{0}$. In particular, lamp drifts or the presence of aerosols, both broadband processes, do not affect the fitting of narrow band structures, which a DOAS retrieval separates from broad band extinction by means of numerical high-pass filtering of the spectra. First attempts have coupled CEAS hardware with a DOAS retrieval algorithm (Meinen et al., 2008), and discussed the peculiarities of differential retrievals in optical cavities (Platt et al., 2009). Platt et al. (2009) showed that the average (1/e) path length in the cavity is given by the following equation:

$\overline{L_{\text {eff }}}(\lambda)=\frac{d_{0}}{1-R(\lambda)+\varepsilon_{\text {Ray }}(\lambda) d_{0}+\varepsilon_{\text {Mie }}(\lambda) d_{0}+\Sigma \sigma_{i} c_{i} d_{0}}$

where $d_{0}$ is the cavity length, $R$ is the mirror reflectivity, $\varepsilon_{\text {Ray }}$, is the extinction due to Rayleigh scattering, $\varepsilon_{\text {Mie }}$ is the extinction due to aerosols and $\sigma_{i}$ is the absorption crosssection of a trace absorber of concentration $c_{i}$. The various extinction processes (denominator of Eq. 1) contribute to the reduction in path length; however past CE-DOAS configurations did not have the means to quantitatively account 
for the reduction in path length caused by temporally variable aerosol extinction, or other causes for variable cavity throughput. The strong sensitivity of Eq. (1) towards aerosol extinction is illustrated in Fig. 1, where the individual extinction losses are shown for our cavity. As the extinction loss becomes larger than the mirror loss or the Rayleigh loss, the effective path length decreases. Furthermore, the different contributions to the overall extinction have different wavelength dependencies. The effective wavelength dependent path length is thus no longer determined exclusively by $R$, and $\varepsilon_{\text {Ray }}$, and their known wavelength dependencies. Aerosols are highly variable in the atmosphere, and as a result the effective path length becomes time dependent. Moreover, the wavelength dependence in Eq. (1) is no longer necessarily well defined. Past attempts to characterize broad band extinction losses by means of separate extinction calibration measurements have mostly been limited to the characterization of mirror reflectivity by the use of $\mathrm{O}_{4}$ in pure oxygen (25 times higher $\mathrm{O}_{4}$ abundance over atmospheric conditions, $\mathrm{O}_{4}$ measured at $446 \mathrm{~nm}$ and $532 \mathrm{~nm}$ bands) (Langridge et al., 2006; Ball and Jones, 2009; Ball et al., 2009), $\mathrm{NO}_{2}$ (using a known $\mathrm{NO}_{2}$ mixture) (Langridge et al., 2006; Venables et al., 2006; Gherman et al., 2008; Triki et al., 2008; Vaughan et al., 2008) or $\mathrm{CO}_{2}$ (Orphal and Ruth, 2008). Aerosol extinction measurements based on relative retrievals have been discussed at red wavelengths (Varma et al., 2009); in the blue spectral range previous attempts to measure aerosol extinction required knowledge of $I_{\mathrm{O}}$ (Washenfelder et al., 2008). An inherent means to calibrate path length in the blue spectral range as a function of wavelength under atmospheric conditions in the presence of variable atmospheric turbulence, aerosols and/or cavity throughput are desirable, and are currently missing.

The blue spectral range holds great potential to detect multiple interesting molecules simultaneously in the atmosphere. Glyoxal is the smallest alpha-dicarbonyl and a novel indicator species for fast photochemistry of volatile organic compounds (VOCs) on local (Volkamer et al., 2005b; Sinreich et al., 2007) and global scales (Kurosu et al., 2005; Wittrock et al., 2006; Vrekoussis et al., 2009). The global CHOCHO source from land ranges between 50 and $108 \mathrm{Tg} \mathrm{vr}^{-1}$, with a single VOC precursor, isoprene, contributing ca. 30\% to the currently known sources (Myriokefalitakis et al., 2008; Fu et al., 2008; Stavrakou et al., 2009), but about half of the terrestrial source is currently unaccounted for (Stavrakou et al., 2009). Recent measurements demonstrate the uncertainties in the amount of glyoxal formed from isoprene (Volkamer et al., 2005a). Current isoprene oxidation schemes consider glyoxal to be only a second and higher generation oxidation product (Bloss et al., 2005; Taraborrelli et al., 2009), while theoretical predictions (Dibble, 2004a,b) suggest a pathway that forms glyoxal also as a first generation product. Such "prompt" formation of glyoxal was demonstrated to form in yields of up to $3 \%$ from the isoprene $+\mathrm{OH}$ reaction (Volkamer et al., 2005a). This corresponds to about an additional

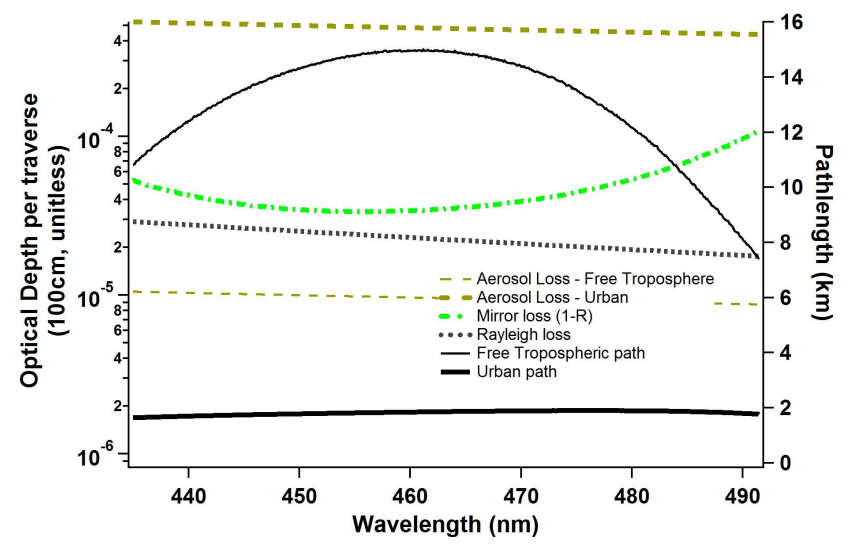

Fig. 1. Aerosols can strongly affect the effective path length. The wavelength dependent extinction losses (dotted lines) are: mirror loss $(1-R)$ of our cavity (green dashed-dotted line), Rayleigh scattering loss of air at $1 \mathrm{~atm}$ (gray dotted line), and aerosol losses for two scenarios: free tropospheric conditions $\left(\varepsilon_{\text {Mie }}=1 \times 10^{-7} \mathrm{~cm}^{-1}\right.$ at $450 \mathrm{~nm}$, thin dashed line); and polluted urban conditions $\left(5 \times 10^{-6} \mathrm{~cm}^{-1}\right.$ at $450 \mathrm{~nm}$, thick dashed line $)$. The wavelength dependence of aerosol extinction was approximated as $\lambda^{-1.5}$. The corresponding effective path length for both scenarios is shown by the respective solid lines.

$10 \mathrm{Tg} / \mathrm{yr}$ of a glyoxal source on global scales that is currently not reflected in atmospheric models. While significant, it does not explain all of the missing glyoxal in biogenic areas. Further, there is also consistent evidence that $\mathrm{CHOCHO}$ is a building block for secondary organic aerosol (SOA) formation (Jang et al., 2002; Hastings et al., 2005; Liggio et al., 2005; Volkamer et al., 2007, 2009b; Galloway et al., 2009; Tan et al., 2009; Ervens and Volkamer, 2010). SOA is a concern for public health (Villalobos-Pietrini et al., 2007) and elevated SOA is linked to increased mortality rates (Pope and Dockery, 2006).

Experimental techniques that are sensitive enough to measure $\mathrm{CHOCHO}$ under atmospheric conditions either rely on derivatization (Yu et al., 1997), or employ long path lengths to directly measure $\mathrm{CHOCHO}$ in the open atmosphere (Volkamer et al., 2005a). Sensitive in-situ techniques with good time resolution are only recently becoming available (Huisman et al., 2008; Washenfelder et al., 2008), and hold great potential to advance our scientific understanding of hydrocarbon and SOA sources on local and global scales. The blue spectral range is particularly attractive, as multiple gases with potential climate relevance are accessible here, e.g., IO and CHOCHO (Volkamer et al., 2010). A typical light source for these instruments is the Xe-arc lamp; however, the use of Xe-arc lamps creates complications in CEAS retrievals, see Fig. 2 in Washenfelder et al. (2008), because Xe-gas emission lines overlap here with the spectral structures of glyoxal and other gases. The spectral intensity and shape of these lines depends on temperature and pressure of the Xe-gas, which fluctuate over time. The 


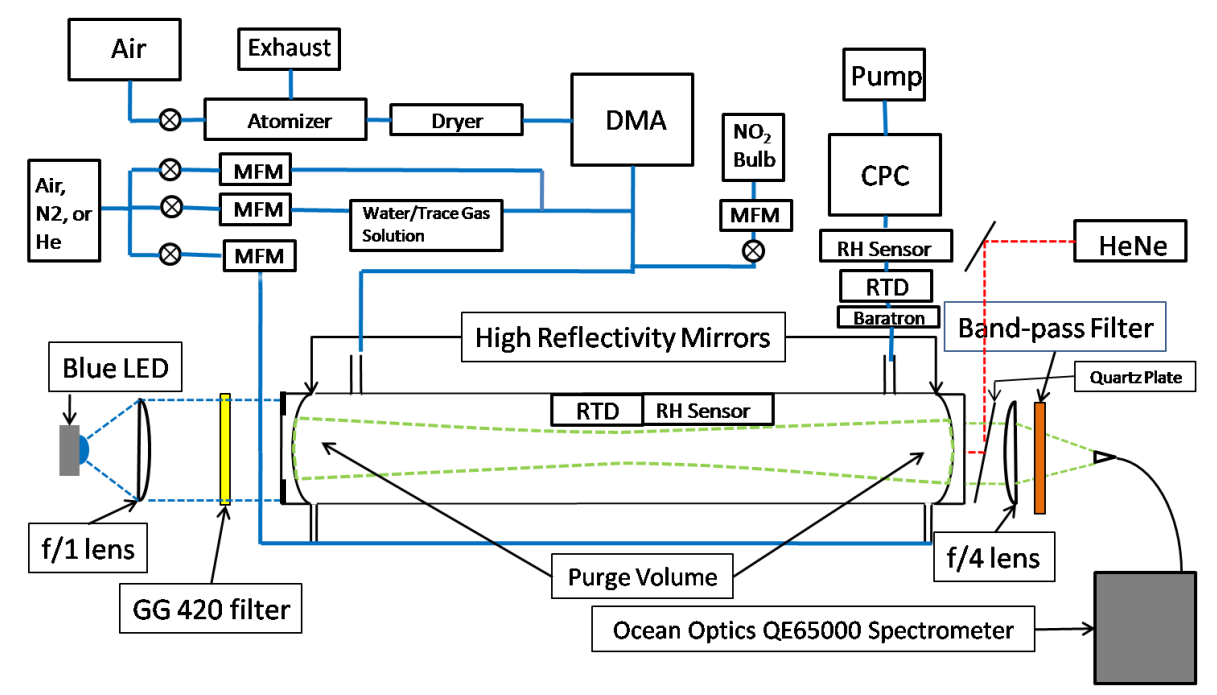

Fig. 2. Schematic of cavity set up and block diagram of flow handling system for aerosol delivery.

resulting temporal variability of the Xe-gas emission lines complicates DOAS applications of Xe-arc lamps in this spectral range. As the number of commercially available highpowered LEDs has increased, LEDs are starting to provide an interesting alternative light source to Xe-arc lamps that is particularly attractive to make the blue spectral range more accessible. Here we present an innovative prototype instrument that actively addresses these challenges, and enables the first inherently calibrated CEAS measurement of trace gases and aerosol extinction in the blue spectral range by a single measurement in open cavity mode under atmospheric conditions.

\section{Experimental}

\subsection{Description of LED-CE-DOAS instrument}

Figure 2 depicts the set up of the LED-CE-DOAS instrument along with the gas delivery and aerosol generation and sizing instrumentation, i.e., an atomizer, differential mobility analyzer (DMA), condensation particle counter (CPC). Light from the LED is collimated and directed into the optical cavity where it makes many passes through the sample volume and is then focused onto the optical fiber and detected by the spectrometer/detector system attached.

\subsubsection{Characterization of LED light sources}

The criteria for a suitable blue LED for LED-CE-DOAS are: (1) lack of a Fabry-Perot etalon; (2) match well with the expected reflectivity of the mirrors (Fig. 3a); (3) high light output, and (4) reasonably small chip size $\left(<1 \mathrm{~mm}^{2}\right)$. Variations of etalon structures, which are periodic emission features arising from the difference in the refractive indices of the coating layers on the LED chip, are caused by fluctuations in either the current (amperage) or the temperature of the LED chip, and can complicate the elimination of spectral features from the LED emission spectrum thus introducing residual structures that limit the sensitivity of the DOAS approach. A good match of LED and $R$ consists in suitable optical power output of the LED, limited out of band light from single pass transmission through the cavity, with the overall effect that the intensity past the cavity is reasonably constant (balanced) over the dynamic range of the detector (Ball et al., 2004; Ball and Jones, 2009). While the presence of etalon structures does not present a fundamental limitation (it can be eliminated by temperature stabilizing the LED, in combination with an extra stable power supply, and/or viewing the LED at an angle) (Kern et al., 2006; Sihler et al., 2009), the absence of etalon structures is desirable.

A variety of blue LEDs were tested. The LED emission spectrum and its spectral stability were characterized both as a function of electrical power and of time. The optical power output was measured using an optical power meter (Thorlabs, $\mathrm{PM}_{210}$ ) (Table 2). The Seoul and LEDengin blue LEDs matched best with the mirror reflectivity, did not show etalon structure, and had optimal emission spectra for the application. In absolute intensity the LEDengin LED was found to be the most powerful LED. Due to the combination of advantages, we chose the LEDengin for our LED-CE-DOAS light source. The LED was mounted to a temperature controlled cooling stage, which was PID stabilized at $10 \pm 0.1^{\circ} \mathrm{C}$, to control variability in the LED output and structure (peak width and dominant wavelength) that vary with the current and temperature. Such stabilization is standard in our laboratory, and not necessarily needed for CE-DOAS applications. 
Table 2. Properties of LEDs that were tested in the blue spectral range.

\begin{tabular}{lllccccc}
\hline Company & Color & Model \# & $\begin{array}{c}\text { Peak } \lambda \\
(\mathrm{nm})\end{array}$ & $\begin{array}{c}\text { Etalon } \\
(\mathrm{Y} / \mathrm{N})\end{array}$ & $\begin{array}{c}\text { Electrical } \\
\text { Power }(\mathrm{W})\end{array}$ & $\begin{array}{l}\text { Optical } \\
\text { Power }(\mathrm{W})\end{array}$ & $\begin{array}{c}\text { Chip Size } \\
(\mu \mathrm{m} \times \mu \mathrm{m})\end{array}$ \\
\hline Phillips-Luxeon & Blue & LXK2-PB14-P00 & 470 & $\mathrm{Y}$ & 3 & 0.216 & $992 \times 992$ \\
Phillips-Luxeon & Royal Blue & LXK2-PR14-P00 & 455 & $\mathrm{Y}$ & 3 & 0.273 & $992 \times 992$ \\
Seoul Semiconductor & Blue & B11190 & 465 & $\mathrm{~N}$ & 1 & 0.180 & $755 \times 755$ \\
LedEngin & Blue & LZ1-00B205 & 465 & $\mathrm{~N}$ & 5 & 1.3 & $1000 \times 1000$ \\
\hline
\end{tabular}

\subsubsection{Characterization of the optical cavity and mirror reflectivity}

The optical cavity (Fig. 2) consists of two 1 inch diameter mirrors with a one meter radius of curvature and a measured reflectivity of $99.9964 \%$ at $455 \mathrm{~nm}$ (Advanced Thin Films- Boulder, CO), which are mounted $99.0 \mathrm{~cm}$ apart. Out of band light was removed using a colored glass filter (Schott GG420) before the cavity and a band-pass filter (Newport 10BPF70-450, $\lambda=450 \mathrm{~nm}, \mathrm{FWHM}=70 \mathrm{~nm}$ ) before the fiber. The effect of the cavity and the optical filters is demonstrated in Fig. 3b. The GG420 is used to avoid saturating the detector while maximizing the use of the detector in the region of interest. The band-pass filter was used to suppress the out of band light at longer wavelengths. If the spectrometer system has any issues with out of band light projection this can introduce stray light into the measurement spectra because the out of band light is orders of magnitude more intense than the measurement light in the region of interest. Light from the LED was collimated into the cavity by a 2 inch diameter $\mathrm{f} / 1$ lens and focused onto the fiber after the cavity by a 1 inch diameter $\mathrm{f} / 4$ lens (Thorlabs). The cavity and mirror mounts are designed so that the cavity can be enclosed using a 1 inch diameter stainless steel or Teflon tube.

After alignment the mirror reflectivity was determined using Rayleigh scattering as described in Washenfelder et al. (2008) by flowing helium in the cavity for a reference spectrum followed by air or nitrogen:

$R(\lambda)=1-d_{0} \frac{\left(\frac{I_{\mathrm{N}_{2}}(\lambda)}{I_{\mathrm{He}}(\lambda)} \varepsilon_{\mathrm{Ray}}^{\mathrm{N}_{2}}(\lambda)\right)-\left(\varepsilon_{\mathrm{Ray}}^{\mathrm{He}}(\lambda)\right)}{1-\left(\frac{I_{\mathrm{N}_{2}}(\lambda)}{I_{\mathrm{He}}(\lambda)}\right)}$,

where $d_{0}$ is the cavity length and $\varepsilon_{\text {Ray }}$ is the extinction due to Rayleigh scattering and $I_{\mathrm{N} 2}$ and $I_{\mathrm{He}}$ are the intensities of the helium and nitrogen spectra respectively.

\subsubsection{The spectrometer and detector systems}

The light exiting the cavity was focused onto an optical fiber. Two different sets of transfer optics and detector systems were used: (1) light was coupled via a 1 inch f/4 lens onto a $1 \mathrm{~mm}$ diameter, $\mathrm{f} / 4$ glass optical fiber (Ocean Optics)

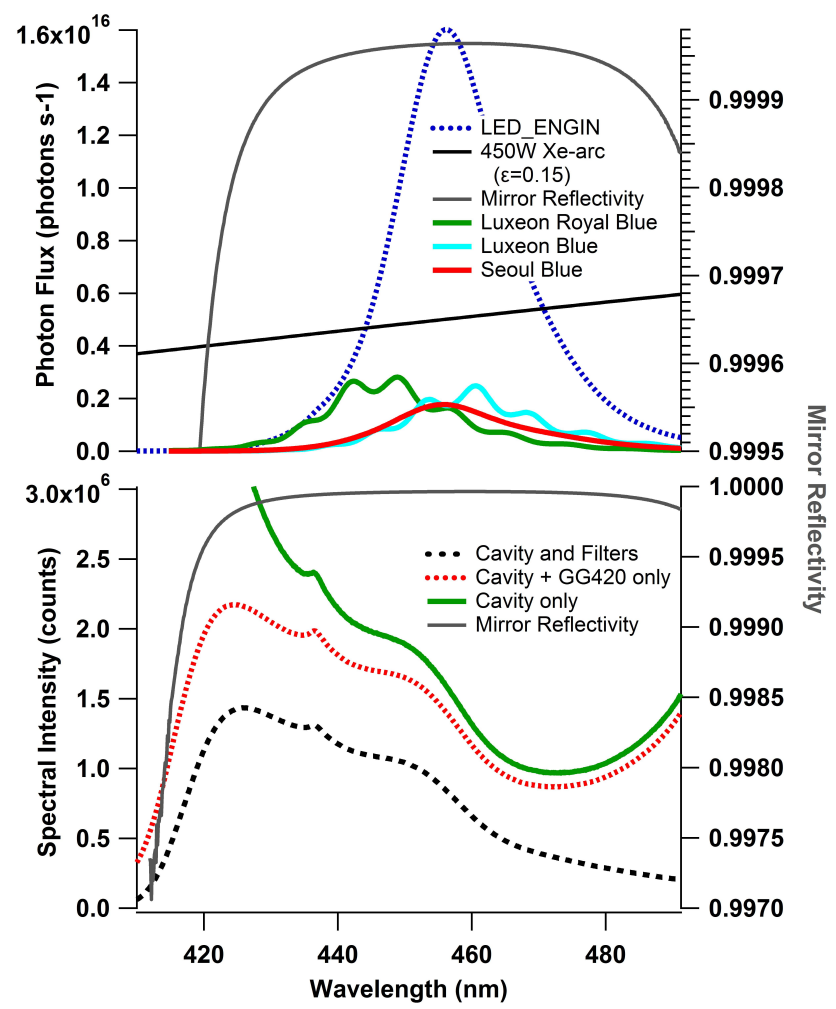

Fig. 3. (A) Emission spectra of several LEDs and a Xe arc lamp compared to mirror reflectivity. (B) Example spectra illustrate the effect of each optical filter element (cavity mirrors, GG420 cut-off filter, band-pass filter) on spectral intensity.

which was coupled to an Ocean Optics QE65000 compact f/4 symmetrical-crossed Czerny-Turner spectrometer. This spectrometer has a $100 \mathrm{~cm}$ focal length and a $100 \mu \mathrm{m}$ slit, and spectra were recorded using a $1.4 \mathrm{~mm}$ high Hamamatsu S7031-1006 $(1024 \times 58$ pixels $)$ CCD detector. The CCD chip was thermo electrically cooled to $-10 . \pm 0.1^{\circ} \mathrm{C}$ in order to reduce dark current of the detector. The spectrometer was heated to $31 . \pm 0.003{ }^{\circ} \mathrm{C}$ (above ambient) to remove temperature drifts in the wavelength pixel mapping of the spectrometer; (2) light was focused via the same lens onto a $1.5 \mathrm{~mm}$ diameter multi-mode single core optical fiber (Ceramoptic) coupled to 27 individual fibers that were distributed 
vertically in front of the slit of an Acton 2300i spectrometer, which was coupled with a PIXIS400 CCD Camera (Roper Scientific). In the Acton 2300i a f/3.9 Czerny-Turner $300 \mathrm{~mm}$ focal length spectrometer was used with a 1200 grooves $/ \mathrm{mm}$ grating blazed at $450 \mathrm{~nm}$. The PIXIS400 camera used a $8 \mathrm{~mm}$ high $26.8 \mathrm{~mm}$ wide back illuminated CCD chip $\left(\mathrm{e} 2 \mathrm{v}{ }^{\circledR}\right.$, $1340 \times 400$ pixels), that was thermoelectrically cooled to $-75 . \pm 0.1^{\circ} \mathrm{C}$ in order to reduce dark current. The spectrometer was heated to $35 \pm 0.1{ }^{\circ} \mathrm{C}$. Both spectrometer/detector systems are fully integrated and controlled by the ATMOSpecLab data acquisition LabVIEW code. The code also reads up to eight temperatures, and contains four PID loops used to control and stabilize temperature (Volkamer et al., 2009a; Coburn et al., 2010).

\subsubsection{Signal to noise comparison}

The signal to noise of the two spectrometer/detector systems was evaluated using the root mean square (RMS) fit residual of the DOAS trace gas fit. The theoretical noise level was calculated using combination of the noise levels of the reference and the sample spectra taken in quadrature where the theoretical noise is: $\Delta$.

( $N$ being the maximum number of counts in the spectra). The integration time used to record the reference spectrum was two minutes for the QE65000, while the Acton/PIXIS reference was $3.5 \mathrm{~min}$. Consecutive spectra were recorded with an integration time of $30 \mathrm{~s}$ and co-added to increase the photon counting statistics. Figure 4 compares the signal to noise ratio of the QE65000 and the Acton/PIXIS spectrometers. The Acton/PIXIS achieves a 2-3 times lower RMS noise for comparable integration times reflecting a 4-9 times higher light throughput. The higher light throughput is primarily due to the high photon collection efficiency of a larger detector with high quantum efficiency, which is systematically exploited by the custom fiber assembly. The spectrometer/detector assembly is described in detail in Coburn et al. (2010).

\subsection{Aerosol generation and measurement}

To characterize the performance of LED-CE-DOAS in the presence of aerosols, mono-disperse aerosols of known size and refractive index were produced using the experimental setup shown in Fig. 2. Polystyrene latex spheres were used as the spherical size-selected aerosol test case. An aqueous solution of polystyrene latex (PSL) spheres (Thermo Scientific, $350 \mathrm{~nm} \pm 7 \mathrm{~nm}$ ) was prepared by suspending ten drops of standard in approximately $200 \mathrm{~mL}$ of de-ionized water. The solution was then volatilized using an atomizer. The airstream was subsequently dried using silica beads, and passed through a Scanning Mobility Particle Sizer (SMPS) which consists of a Differential Mobility Analyzer (DMA) (TSI model 3081) and a Condensation Particle Counter (CPC) (TSI 3022A, in high flow mode) used to size

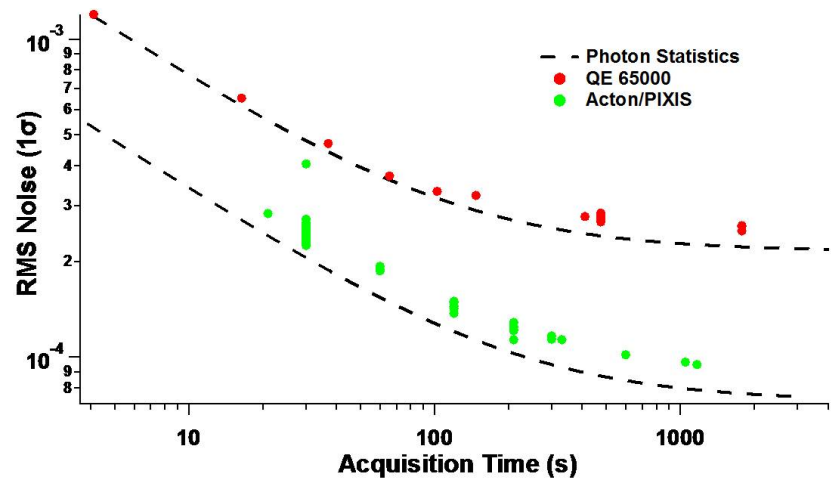

Fig. 4. RMS Photon noise as a function of acquisition time as measured by the two spectrometer/detector systems used in this study. The theoretical limit of the noise reduction is shown by the dashed lines.

select and count particles. The SMPS was set to $5 \mathrm{lpm}$ (liters per minute) sheath flow and the sample flow through the DMA was 500 standard cubic centimeters per minute $(\mathrm{sccm})$. The size of the aerosols selected by the DMA is known to a 3\% uncertainty (Biskos et al., 2006). Particles were counted by the CPC before and after passing through the cavity, and numbers were found identical to within less than $1 \%$ indicating negligible particle losses inside the cavity. The mirrors were kept clean using a dry air purge at the ends of the cavity and the sample (aerosols and/or trace gases) was supplied in the middle of the enclosed cavity volume (Fig. 2).

\subsection{Trace gas generation}

Water was introduced in the flow volume after the aerosols had been selected by passing a dilution flow through a flask of de-ionized water (Fig. 2) and passed through a PFA Teflon ${ }^{\circledR}$ filter in a PFA Teflon ${ }^{\circledR}$ filter holder to remove any water droplets. Relative humidity (Honeywell, 4000$003, \pm 3.5 \% \mathrm{RH})$ and temperature (Omega RTD, $\pm 0.01^{\circ} \mathrm{C}$ ) were measured at the center of the cavity, while pressure (MKS Baratron $629, \pm 0.12 \%$ of reading) was measured as the airstream exited the cavity. For closed cavity measurements, glyoxal, methyl glyoxal and $\mathrm{NO}_{2}$ were generated, and supplied to the cavity as shown in Fig. 2. Air was bubbled through a solution of glyoxal and methyl glyoxal and then diluted before the cavity to provide both trace gases and water to the cavity. $\mathrm{NO}_{2}$ was supplied from a standard bulb filled to a starting pressure of 830 Torr and a mixing ratio of $4 \times 10^{-7}$ and then a small flow was leaked from the bulb, measured by a mass flow meter (Sierra Instruments) and diluted by the larger airstream. The $\mathrm{NO}_{2}$ flow changed slowly over time as the pressure in the bulb reduced. The methyl glyoxal and glyoxal concentrations varied over time as a result of the difference in their respective Henry's Law coefficients (Betterton and Hoffmann, 1988; Ip et al., 2009). 
Iodine monoxide measurements were made in closedcavity mode. IO was generated via the reaction of ozone with iodine atoms as described by the mechanism outlined in Gomez-Martin et al. (2007). A $20 \mathrm{sccm}$ flow of air was passed first through a flask that contained iodine crystals (Fisher Scientific) cooled in an ice bath and flowed into another flask equipped with an atomic $\mathrm{Hg}$ line emission lamp and a Xe line emission lamp (UVP). The $\mathrm{Hg}$ lamp was switched on briefly to produce ozone in the flask. The Xe lamp was on continuously, and produced iodine atoms by the photolysis of $I_{2}$, which then reacted with the ozone to make IO. The flow was diluted into a $1000 \mathrm{sccm}$ total flow into the instrument. After exiting the cavity an ozone monitor (ThermoFisher Scientific, 49i) measured the amount of ozone in the sample flow.

For open cavity measurements the tube enclosing the cavity was removed and a curtain flow was maintained on the mirrors, allowing both mirrors to face the open room air. $\mathrm{NO}_{2}$ and water were present in the room air in sufficiently high concentrations that no further supply was needed. Glyoxal and methyl glyoxal were introduced to the light path by placing a row of Petri dishes containing solutions of glyoxal and methyl glyoxal directly under the light path so that the solutions evaporated into the light path.

\section{Results}

\subsection{LED light source}

The LEDengin LED used here is 5 times more powerful than the Luxeon and is more powerful than the calculated output of the Xe arc (Fig. 3a). The LED also overcomes the limitation created by the highly unstable Xe emission lines that fall in the middle of the $\mathrm{CHOCHO}$ evaluation range (see e.g., Washenfelder et al., 2008). Because the LED emits less light at wavelengths where the mirror reflectivity drops (out of band light) than a Xe-arc lamp less filtering is needed to remove out of band light. Out of band light is orders of magnitude more intense than the sample light because of the drop in mirror reflectivity (more light allowed through the cavity). The reduced need for filtration allows for a wider useable wavelength range (420-490 nm) compared to arc lamp IBBCEAS setups (see Table 1), and helps increase light throughput by reducing optical surfaces.

Another advantage of the light source that has been exploited in our LED-CE-DOAS instrument is that the center wavelength of the LED can be chosen to match the wavelength of maximum mirror-reflectivity. This enables us to use the mirror in order to balance the light intensity across the detector. The effect of the mirror is illustrated in Fig. 3b, and enables us to measure a particularly broad spectral range that is $70 \mathrm{~nm}$ wide. This is wider than previous CEAS instruments, see Table 1. Our motivation in systematically widening the spectral range is innovative, because in contrast to previous work it is chosen to include measurement of the $\mathrm{O}_{4}$ absorption band at $477 \mathrm{~nm}$, together with the other gases. The $\mathrm{O}_{4}$ absorption cross section is $>10$ times stronger at $477 \mathrm{~nm}$ than at $446 \mathrm{~nm}$. That strong $\mathrm{O}_{4}$ band, and the water bands at $443 \mathrm{~nm}$ provide us with independent means to measure under atmospheric conditions even small variations in the effective extinction length of photons from the cavity at two wavelengths, as part of each individual spectrum. Such variations could be caused by atmospheric turbulence or variable aerosol optical depth. By measuring the decrease in the $\mathrm{O}_{4}$ and $\mathrm{H}_{2} \mathrm{O}$ SCDs compared to clean (aerosol free) air, CEDOAS in principle allows for the differential measurement of aerosol optical depth.

\subsection{DOAS retrieval and absorption cross section weighting}

A data analysis routine has been developed using the WinDOAS spectral fitting program (Fayt and Van Roosendael, 2001). The algorithm uses as input the high-resolution molecular absorption cross-section spectra of glyoxal (296 K) (Volkamer et al., 2005c), methyl glyoxal (296 K) (Meller et al., 1991), $\mathrm{O}_{4}$ (Hermans, 2010), $\mathrm{H}_{2} \mathrm{O}$ (833 mbar, $296 \mathrm{~K}$ ) (Rothman et al., 2006), $\mathrm{NO}_{2}$ (294 K) (Vandaele et al., 2002) and IO (Hönninger, 1999). These spectra are convoluted with the slit function of the spectrometer and interpolated onto the wavelength dispersion of the spectrometer. Two fit ranges were used, one for the trace gases (435$465 \mathrm{~nm})$ and one for $\mathrm{O}_{4}(455-487 \mathrm{~nm})$ each of these used a 4-th order polynomial for the high pass filter. The crosssections are then fitted to the measured optical density to retrieve the slant column density (SCD, integrated concentration along a given path length). Other degrees of freedom of the non-linear least-square fitting routine are kept to a minimum in our retrieval, i.e., no spectral shift and intensity offset are allowed. The slant columns are converted to concentrations using the path length calibration.

DOAS uses Lambert Beer's Law:

$\ln \left(\frac{I_{0}}{I}\right)=\sigma(\lambda) c l(\lambda)$

in a modified form that separates extinction processes as broadband and narrow-band (differential) processes:

$$
\begin{aligned}
& \ln \left(\frac{I_{0}}{I}\right)=\left[\Sigma \sigma_{i}^{\prime}(\lambda) c_{i}+\Sigma \sigma_{\mathrm{b}, i}(\lambda) c_{i}+\varepsilon_{\mathrm{Ray}}\right. \\
& \left.+\varepsilon_{\mathrm{Mie}}+T(\lambda)\right] l=\left[\Sigma \sigma_{i}^{\prime}(\lambda) c_{i}+\text { polynominal }\right] l
\end{aligned}
$$

where $I_{0}$ and $I$ are the reference and measurement intensities respectively and $\sigma, c$ and $l$ are the absorption crosssection, concentration and absorption path length, respectively; $\sigma^{\prime}{ }_{i}$ is the differential (narrow band) portion of the absorption cross-section, $\sigma_{\mathrm{b}, i}$ is the broadband component, $\varepsilon_{\text {Ray }}$ is the extinction from Rayleigh scattering, $\varepsilon_{\text {Mie }}$ is the extinction from aerosols due to Mie scattering, and $T$ is the 
instrument transfer function. A polynomial (or other form of a high pass filter) is used to represent all broadband processes $\left(\sigma_{\mathrm{b}}\right.$, both Rayleigh and Mie scattering and $T$ ), while the trace gases of interest are identified and quantified by their characteristic differential absorption structure. This application of Beer's law assumes that path length is constant within the wavelength interval used for the DOAS fit. However, in CEAS applications the effective path length, $L_{\text {eff }}$, varies strongly with wavelength, as given by Eq. (1), and illustrated in Fig. 1. The resulting wavelength dependence of path length creates residual structures if spectra are linearly scaled in the respective fit windows. The effect is illustrated in Fig. 5 for a DOAS retrieval of glyoxal. For weak absorbers in a Rayleigh atmosphere (no aerosols), the cavity enhancement factor in BB-CEAS retrievals accounts for the wavelength dependence in path length and converts the optical density into extinction units (Fiedler et al., 2003; Washenfelder et al., 2008). For strong absorbers, the trace gas can further become self-limiting to path length at the center of an absorption band. This effect is discussed at a single wavelength by Platt et al. (2009). In this work all trace gas absorbers are optically thin (differential optical density $<4 \%$ ), and the effect to self-limit path length is negligible. However, as illustrated in Fig. 1, aerosols can strongly modify the wavelength dependence of path length. Spectral distortions in DOAS applications are observed for various reasons (Platt et al., 2009). A generalized solution consists in a variation of the interpolation approach (Volkamer et al., 1998) that interpolates differential absorption between two extreme cases: (1) the Rayleigh case and (2) an upper limit aerosol extinction (here $\varepsilon_{\text {Mie }}=8 \times 10^{-7} \mathrm{~cm}^{-1}$ ). We create the effective cross-sections, $\bar{\sigma}_{\text {eff }}(\lambda)$ as follows:

$\bar{\sigma}_{\text {eff }}(\lambda)=\sigma(\lambda) F(\lambda)$

where the weighing factor, $F(\lambda)$, accounts for the relative variation of the wavelength dependence of path length; $F$ is calculated as follows:

$F(\lambda)=\frac{L_{\text {eff }}(\lambda)}{L_{\text {eff }}(\text { peak } \lambda \text { of absorption })}$

where $L_{\text {eff }}$ is calculated according to Eq. (1), and normalization is most useful with respect to a wavelength where the path length is well known. At that wavelength $F$ takes the value of unity (no scaling); $F$ varied from $0.7<F<1.2$ for the spectral windows fitted, see Fig. S2 in the Supplement. This notation decouples the relative variation of path length over a fitting window $(F)$ from the absolute value of $L_{\mathrm{eff}}$ at the wavelength of normalization. At any point in time $L_{\text {eff }}$ is well defined at two wavelengths in our system, i.e., at $477 \mathrm{~nm}$ from measurements of $\mathrm{O}_{4}$ :

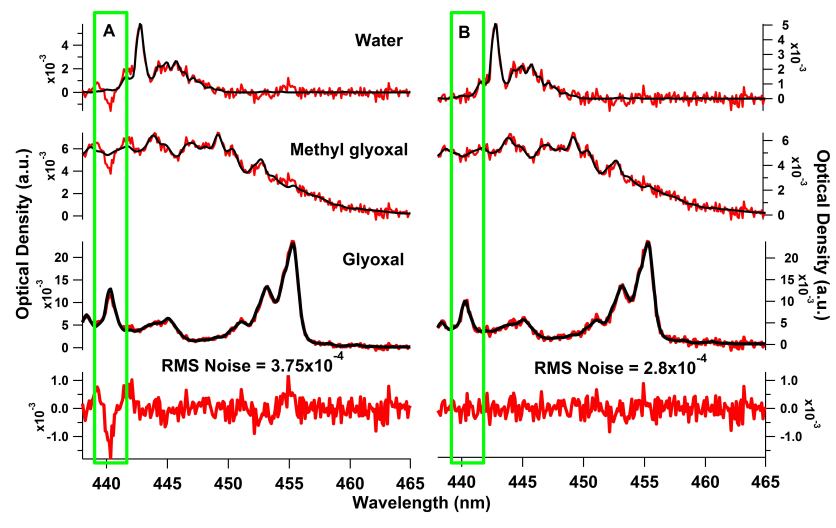

Fig. 5. Effects of wavelength dependent path length on the fit residual. (A) An unscaled glyoxal cross-section is fitted to the spectra. (B) Scaled glyoxal cross-section fit (Eqs. 5 and 6, Rayleigh case in $\mathrm{N}_{2}$ ). Cross-section scaling is able to reduce the RMS by eliminating systematic residual structures. The experimental conditions are: $[$ glyoxal $]=1.45 \mathrm{ppbv},[$ methylglyoxal $]=2.05 \mathrm{ppbv},\left[\mathrm{H}_{2} \mathrm{O}\right]=0.59 \%$.

$$
\begin{aligned}
& \overline{L_{\text {eff }}}(477 \mathrm{~nm})=\frac{\mathrm{SCD}_{\mathrm{O}_{4,477 \mathrm{~nm}}}}{\mathrm{~N}_{\mathrm{O}_{2}}^{2}} \\
& =\frac{d_{0}}{1-R_{477 \mathrm{~nm}}+\varepsilon_{\text {Ray }, 477 \mathrm{~nm}} d_{0}+\varepsilon_{\text {Mie, }, 477 \mathrm{~nm}} d_{0}+\Sigma \sigma_{i} c_{i} d_{0}}
\end{aligned}
$$

and at $443 \mathrm{~nm}$ from measurements of water:

$$
\begin{aligned}
& \overline{L_{\text {eff }}}(443 \mathrm{~nm})=\frac{\mathrm{SCD}_{\mathrm{H}_{2} \mathrm{O}, 443 \mathrm{~nm}}}{\mathrm{~N}_{\mathrm{H}_{2} \mathrm{O}}} \\
& =\frac{d_{0}}{1-R_{443 \mathrm{~nm}}+\varepsilon_{\text {Ray }, 443 \mathrm{~nm}} d_{0}+\varepsilon_{\text {Mie }, 443 \mathrm{~nm}} d_{0}+\Sigma \sigma_{i} c_{i} d_{0}}
\end{aligned}
$$

where $\mathrm{SCD}_{\mathrm{O} 4}$ has units of molec $^{2} \mathrm{~cm}^{-5}$, and $\mathrm{N}_{\mathrm{O} 2}$ is the number density of molecular oxygen in units of molec $\mathrm{cm}^{-3}$, and $\mathrm{SCD}_{\mathrm{H} 2 \mathrm{O}}$ has units of molec $\mathrm{cm}^{-2}$, and $\mathrm{N}_{\mathrm{H} 2 \mathrm{O}}$ is the number density of water in units of molec $\mathrm{cm}^{-3}$, else see Eq. (1). Only in situations where the wavelength dependence of $F$ is highly variable an interpolation between two extreme cases of effective cross-sections needs to be fitted simultaneously and the scaling factors derived from the non-linear fit are summed. In most situations it is sufficient to derive a single appropriately scaled $F$ that is applied to all cross sections; this is preferred, as fitting only one cross-section per gas minimizes the degrees of freedom in a respective fit window and makes fitting more stable. Our approach accounts for spectral distortions due to mirror- (Fiedler et al., 2007), Rayleigh(Washenfelder et al., 2008) and/or self-limited path length (Platt et al., 2009), and extends beyond these effects by providing a generalized view on wavelength dependent extinction. We demonstrate a practical solution to experimentally constrain the wavelength dependence of aerosol extinction from observing pairs of trace gases, i.e., $\mathrm{O}_{4}$ and $\mathrm{NO}_{2}$ or $\mathrm{O}_{4}$ and $\mathrm{H}_{2} \mathrm{O}$ (see Sect. 3.8). Measurements of $\mathrm{O}_{4}$ and water in the blue spectral range at ambient conditions require 
high reflectivity mirrors and low photon shot-noise (strong light sources) as pre-requisites; inherent path length calibration thus should be considered as an option when choosing mirror reflectivity; other factors are discussed by Fiedler et al. (2007); Platt et al. (2009).

\subsection{Determination of sample path, $d_{\mathrm{s}}$}

As depicted in Fig. 2, the aerosol and trace gas samples do not occupy the entire length of the cavity; the length of the volume $\left(d_{\mathrm{S}}\right)$ must be determined by a separate set of experiments. This is done by flowing a known amount of an absorber through the sample portion of the cavity. In each run of the experiment before aerosols were introduced, humidified air was flowed through the cavity and the water vapor concentration was measured by the combination of relative humidity sensor, RTD and the pressure sensor. The ratio $d_{\mathrm{s}} / d_{0}$ is then calculated as the ratio of the retrieved light path for the water $\left(\mathrm{H}_{2} \mathrm{O}\right.$ SCD divided by concentration calculated from the RH) and the theoretical path, Eq. (1), at the wavelength of the water band. The sample path is then calculated by multiplying this ratio by $d_{0}$. This can also be done using $\mathrm{O}_{4}$ by flowing nitrogen in the purge volumes, and compressed air at known pressure in the cavity. Use of synthetic air requires characterization of the oxygen mixing ratio separately. In this experiment $d_{0}=99 . \pm 0.1 \mathrm{~cm}$ and $d_{\mathrm{s}}=83 \pm 1 \mathrm{~cm}$.

\subsection{Accounting of broadband extinction by Polynomial order}

In DOAS retrievals, fitting a polynomial is one means of numerical high pass filtering of spectra to represent broadband extinction, see Eq. (4). The wavelength dependence of the mirror reflectivity is a primary factor that imposes a broadband shape to the collected spectra in Rayleigh atmospheres. This variation in the number of times that $R \mathrm{im}-$ poses its wavelength dependence is systematically exploited in Washenfelder et al. (2008) for the case of gases with different Rayleigh scattering cross sections to calculate mirror reflectivity over a wide wavelength range, Eq. (2). However, the imposition of $R$ is also relevant to other cases of variable extinction (e.g., aerosols), and needs to be captured accurately in DOAS retrievals. When the cavity is sequentially filled with gases of different Rayleigh cross-sections, for example helium compared to nitrogen, or with air and aerosol compared to nitrogen only, the difference in the number of passes, $\Delta n$, is significant, and the mirror imposes its wavelength dependence according to a power law, i.e., $R^{\Delta n}$. The interpolation approach described in Sect. 3.2 can account for such variable wavelength dependence of extinction. An alternative means is to account for the variability in wavelength dependence of extinction by a suitable polynomial. A set of sensitivity studies were carried out that compared $\mathrm{He}$ and air spectra, and/or the Rayleigh case with an aerosol laden
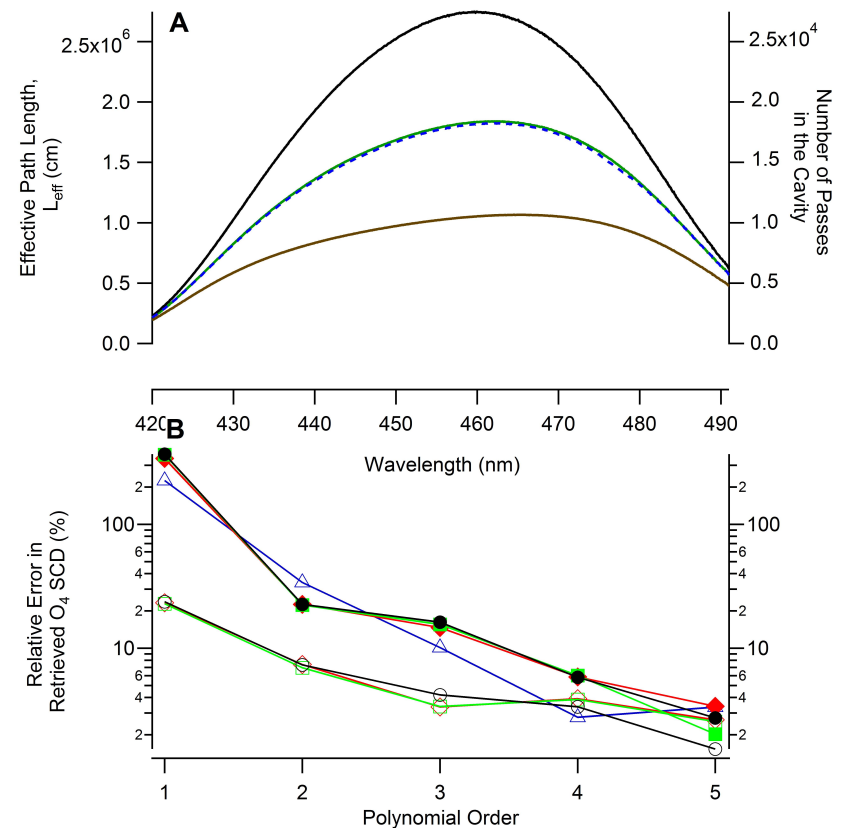

Fig. 6. Effect of mirror reflectivity and high pass filter on the $\mathrm{O}_{4}$ retrieval. (A) Effective path length and number of traverses in the cavity in helium (black), nitrogen (green), air (blue) and air with aerosol (brown, $\varepsilon_{\text {Mie }}=3 \times 10^{-7} \mathrm{~cm}^{-1}$ ) calculated from theory using known Rayleigh cross-sections and the aerosol extinction crosssection from Mie theory (Bodhaine et al., 1999; Sneep and Ubachs, 2005). (B) The relative error in the retrieved $\mathrm{O}_{4}$ slant column retrieved compared to the calculated $\mathrm{O}_{4}$ slant column as a function of polynomial order of the high pass filter. Open green squares: air spectrum fit against a nitrogen reference with $F$ (Eq. 5) for the Rayleigh case; open black circles: air spectrum, nitrogen reference, Aerosol case scaled cross-section; open red diamonds: air spectrum, nitrogen reference, sum of two cross-section fit; open blue triangles: air spectrum, He reference, Rayleigh case crosssection; closed green squares: Aerosol spectrum, nitrogen reference, Rayleigh case cross-section; closed black circles: aerosol spectrum, nitrogen reference, Aerosol case cross-section; closed red diamonds: aerosol spectrum, nitrogen reference, sum of two crosssection fit.

cavity, to test this. The results are shown in Fig. 6. It is found that a higher order polynomial ( $>3$-rd) is capable to account for the wavelength dependent intensity change between the reference and the measurement spectra. Notably, if the wavelength dependence of extinction is not adequately accounted for, this can cause spectral cross-correlations, as illustrated in Fig. $6 \mathrm{~b}$ for the retrieved $\mathrm{O}_{4} \mathrm{SCD}$. The error in the retrieved $\mathrm{O}_{4} \mathrm{SCD}$ is $12 \%$ for a 3-rd degree polynomial, and higher for lower order polynomials. Higher order polynomials significantly reduce this error. For the case of comparing a $\mathrm{He}$ and air spectrum, Fig. $6 \mathrm{~b}$ demonstrates that the observed $\mathrm{O}_{4}$ matches to within better than $3 \%$ of the $\mathrm{O}_{4}$ SCD inferred from knowledge of $\mathrm{R}$ and the Rayleigh cross section for a polynomial order of 4 and higher. Shifting the 
Table 3. Detection Limits $(2 \sigma)$ for species in an aerosol free and an urban environment $\left(\varepsilon_{\text {Mie }}=5 \times 10^{-6} \mathrm{~cm}^{-1}\right.$ at $\left.450 \mathrm{~nm}\right)$.

\begin{tabular}{lll}
\hline Species Detected in 1 min & $\begin{array}{l}\text { Aerosol Free } \\
(L=11-14 \mathrm{~km})\end{array}$ & $\begin{array}{l}\text { Urban Environment } \\
(L=1.8 \mathrm{~km})\end{array}$ \\
\hline CHOCHO & $19 \mathrm{pptv}$ & $190 \mathrm{pptv}$ \\
$\mathrm{CH}_{3}$ COCHO & $170 \mathrm{pptv}$ & $1.5 \mathrm{ppbv}$ \\
$\mathrm{NO}_{2}$ & $30 \mathrm{pptv}$ & $290 \mathrm{pptv}$ \\
$\mathrm{IO}$ & $0.7 \mathrm{pptv}$ & $4.4 \mathrm{pptv}$ \\
Water & $280 \mathrm{ppm}$ & $0.3 \%$ \\
$\mathrm{O}_{4}$ & $0.1 \% *$ & $0.8 \%$ \\
\hline
\end{tabular}

* Calculated as the equivalent error of the $\mathrm{O}_{2}$ volume mixing ratio of air at STP.

wavelength dependence of extinction into the polynomial order thus presents a viable option; this approach reduces the number of effective cross sections to be fitted simultaneously as the sum of the extreme cases performs with similar accuracy to either of the two other cases. Notably, a key advantage of the DOAS optimized retrieval is that the residual RMS alerts of an incorrectly captured wavelength dependence of extinction and/or self-limitation in path length, as both effects can cause residual RMS that contain systematic structures (see Fig. 5a). In absence of such "alerting" structures (i.e., purely statistical RMS), a single set of precalculated effective cross sections (one per gas) is sufficient also if the overall cavity extinction, and its wavelength dependence are variable.

\subsection{Methyl glyoxal measurement}

In addition to glyoxal and $\mathrm{NO}_{2}$, methyl glyoxal was detected with the LED-CE-DOAS instrument. The spectral proof is shown for an example retrieval in Fig. 5. The detection sensitivity of methyl glyoxal is approximately ten times less than that of glyoxal due to the smaller absorption cross-section. This lower sensitivity combined with the lower concentrations of methyl glyoxal make an atmospheric detection unlikely with our instrument. However, the sensitivity is high enough to be useful for the detection of methyl glyoxal in atmospheric simulation chambers where methyl glyoxal concentrations are higher. Detection limits for glyoxal, methyl glyoxal, $\mathrm{IO}, \mathrm{NO}_{2}$, water and $\mathrm{O}_{4}$ were calculated conservatively by taking two times the RMS noise of the fit residual and dividing by the peak differential cross-section and the path length; in Table 3 typical values for the detection limit are given for the free troposphere (aerosol free) and an urban environment (aerosol extinction $=5 \times 10^{-6} \mathrm{~cm}^{-1}$ ).

\subsection{IO and $\mathrm{I}_{2}$ measurement}

IO was measured by the instrument in the presence of $I_{2}$ and ozone. Both the ozone absorption in the Huggins band, and the molecular iodine absorption provide broadband extinctions in the cavity. Because the measured ozone

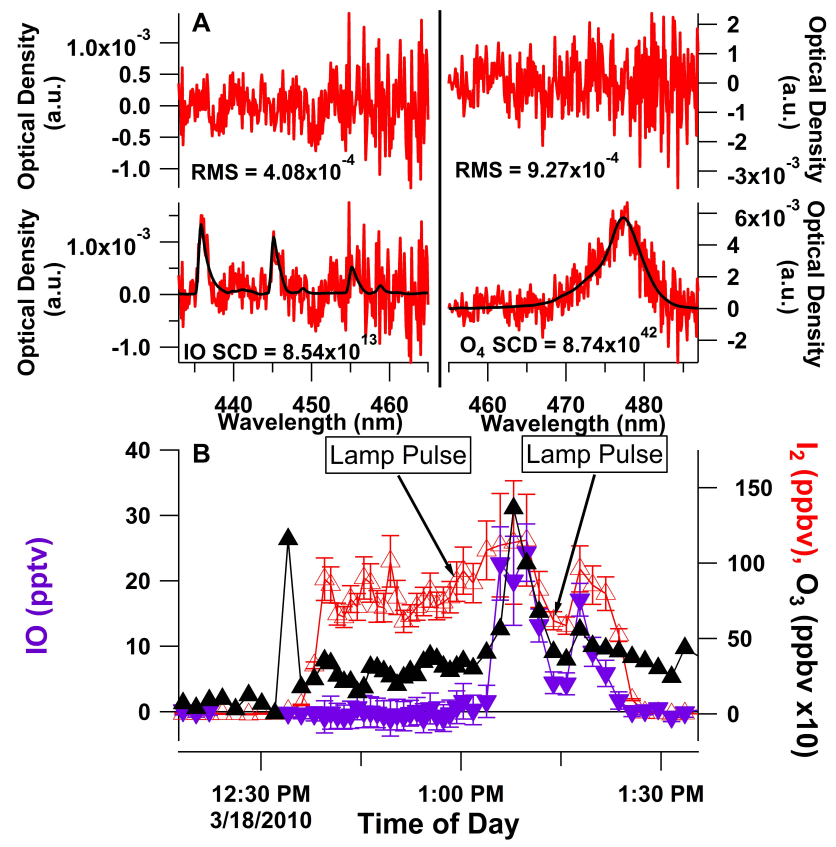

Fig. 7. (A) Example spectrum for the IO detection (4.4 pptv IO, 62 ppbv $\mathrm{I}_{2}$ ) (left panel) with the corresponding $\mathrm{O}_{4}$ fit (right panel). (B) Time trace showing the variations in $\mathrm{IO}, \mathrm{O}_{3}$ and $\mathrm{I}_{2}$, as inferred from the reduction in $\mathrm{O}_{4}$ path length. The detection limits for IO (dashed line) and $\mathrm{I}_{2}$ (dotted line) increase towards longer wavelengths because of extinction losses due to $\mathrm{I}_{2}$.

concentration $\left(<20 \mathrm{ppbv}\right.$, an extinction of $2 \times 10^{-10} \mathrm{~cm}^{-1}$ at $477 \mathrm{~nm}$ ) was not high enough to change the path length in the cavity; absorption by iodine was then the only broadband extinction process within the DOAS analysis windows. While IO can nucleate particles, such nano-particles are inefficient in their interaction with light at our wavelengths: the extinction cross section of a $10 \mathrm{~nm}$ diameter particle $(n=1.50)$ is on the order of $10^{-18} \mathrm{~cm}^{2}$ particle ${ }^{-1}$ at $450 \mathrm{~nm}$, which corresponds to an extinction of $1 \times 10^{-11}$ for $1 \times 10^{5}$ particles $\mathrm{cm}^{-3}$. The absence of other broadband extinction processes was further verified by a BBCEAS analysis of the spectra. This allowed the $\mathrm{I}_{2}$ concentration to be retrieved in a similar manner to the aerosol extinction by the measurement of $\mathrm{O}_{4}$, Eq. (8). The $\mathrm{I}_{2}$ concentration was then used in combination with the wavelength dependence of the $\mathrm{I}_{2}$ spectrum, and the mirror reflectivity curve to calculate the absorption path length for IO. Sample spectra are shown in Fig. 7a. A 1.5 pptv minimum detection limit for IO for a 2 min integration time using the QE65000 spectrometer was calculated (Fig. 7b). The somewhat poorer detection sensitivity towards $\mathrm{IO}$ in this experiment compared to that listed in Table 3 is due to the greatly reduced path length and higher RMS caused by the $I_{2}$ absorption for a concentration that is orders of magnitude higher than that found in the marine background. Notably, in a reasonably moist atmosphere (see Table 3) the path length at the blue end of our spectral range is constrained more directly from observing water. 


\subsection{Aerosol extinction measurements}

For measurements in the ambient atmosphere, aerosols are likely the largest contributor to extinction and thus reduce the path length in the cavity (see Fig. 1). Aerosol extinction can be inferred from the change in the measured path in the presence of aerosols, compared to the path in the empty cavity (determined by separate measurements of $R$, Sect. 2.1.2, and knowledge of the Rayleigh scattering cross section of air, and air pressure). The aerosol extinction was calculated using a modified version of Eq. (1), with the substitution of $d_{\mathrm{s}}$ (the sample length) for $d_{0}$ (the cavity length) for aerosols and trace gases:

$\varepsilon_{\text {aer }}(\lambda)=\frac{\left(\frac{d_{0}}{\overline{L_{\text {aer }}}(\lambda)}\right)-1+R(\lambda)-\varepsilon_{\text {Ray }}(\lambda) d_{0}}{d_{\mathrm{s}}}$

This can be simplified if the sample path for the aerosols and the reference absorber are the same:

$$
\begin{aligned}
\varepsilon_{\mathrm{aer}}(\lambda) & =\frac{d_{0}}{d_{\mathrm{s}}}\left(\frac{1}{\overline{L_{\mathrm{aer}}}(\lambda)}-\frac{1}{\overline{L_{0}}(\lambda)}\right) \\
& =\frac{d_{0}}{d_{\mathrm{s}}} \mathrm{O}_{2_{\mathrm{vmr}}}^{2} \frac{\frac{1}{\operatorname{SCD}_{\mathrm{O}_{4, \text { aer }}}}}{N_{\mathrm{d}, \text { aer }}^{2}}-\frac{\frac{1}{\operatorname{SCD}_{\mathrm{O}_{4, \text { Ray }}}}}{N_{\mathrm{d}, \text { Ray }}^{2}}
\end{aligned}
$$

where $L_{\text {aer }}$ is the path in the presence of aerosols and $L_{0}$ is the path for the Rayleigh case in a clean cavity filled with air (see Eq. 1), $d_{0}$ and $d_{\mathrm{s}}$ are defined in Sect. 3.3, $N_{\mathrm{d}}$ is the density of air $\left(N_{\mathrm{d}}=2.09 \times 10^{19}\right.$ molecules $\mathrm{cm}^{-3}$ at a pressure of $830 \mathrm{mbar}$ and a temperature of $298 \mathrm{~K}$ ) in the aerosol (and reference) case, $\mathrm{O}_{2 \text {,vmr }}$ is the oxygen volume mixing ratio of air (0.2095), the $\mathrm{SCD}_{\mathrm{O}_{4, \text { Ray }}}$ is the column density of the oxygen dimer in air, and $\varepsilon_{\text {Ray }}$ is the extinction due to Rayleigh scattering. The $\mathrm{SCD}_{\mathrm{O}_{4, \text { arr }}}$ is measured and the $\mathrm{SCD}_{\mathrm{O}_{4, \text { Ray }}}$ is calculated. (Please make sure that the $\mathrm{O}_{4}$ and and Ray are in the subscript as the appear in Eq. 9). Two different approaches were used to retrieve the aerosol extinction. The first approach used the change in the retrieved SCD of $\mathrm{O}_{4}$ at $477 \mathrm{~nm}$ combined with the independent measurement of pressure and temperature and the knowledge of the oxygen mixing as given in Eq. (9). The second used a modified version of Eq. (9), using the SCD of water measured at $443 \mathrm{~nm}$ in a similar fashion to $\mathrm{O}_{4}$, and relative humidity, pressure and temperature were measured separately to calculate the number density of water molecules in $\mathrm{cm}^{3}$ of air. The detection limit for aerosol extinction is $1.6 \times 10^{-8} \mathrm{~cm}^{-1}$ at $477 \mathrm{~nm}$ and $1 \times 10^{-7} \mathrm{~cm}^{-1}$ at $443 \mathrm{~nm}$.

\subsection{Comparison to Mie theory}

The aerosol extinctions as retrieved from the reduction of the path length in the cavity were compared to Mie theory. The wavelength dependence of the refractive index of the mono-disperse PSLs was calculated based on the Cauchy

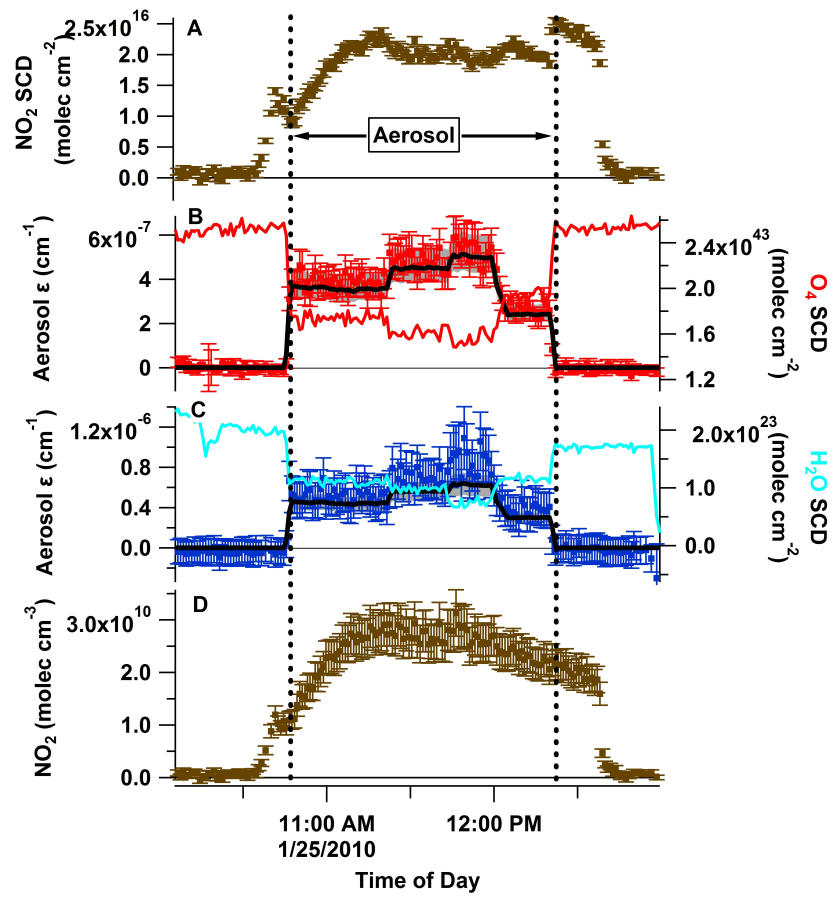

Fig. 8. Simultaneous retrieval of $\mathrm{NO}_{2}$ and aerosol extinction at two wavelengths in closed cavity mode. (A) Retrieved $\mathrm{NO}_{2}$ slant column density. (B) $\mathrm{O}_{4}$ SCD (Red Line) and aerosol extinction retrieved from $\mathrm{O}_{4}$ absorption at $477 \mathrm{~nm}$ (red dots) compared to Mie theory (black line, gray area represents uncertainty in size of $350 \mathrm{~nm}$ PSLs); (C) $\mathrm{H}_{2} \mathrm{O}$ SCD and aerosol extinction retrieved from water absorption at $442.8 \mathrm{~nm}$ (blue dots) compared to theory (black line); (D) $\mathrm{NO}_{2}$ concentration corrected for the change in path length measured using $\mathrm{O}_{4}$.

expression terms given in the PSL sphere datasheet (ThermoFisher Scientific Technical Note TN007.03). The aerosol scattering cross-section was then calculated using Mie theory. The scattering cross-section for a $350 \pm 15 \mathrm{~nm}$ PSL $\left(\sigma_{443 \mathrm{~nm}}=3.54 \times 10^{-9} \mathrm{~cm}^{2}, \sigma_{477 \mathrm{~nm}}=2.84 \times 10^{-9} \mathrm{~cm}^{2}\right)$ was multiplied by the measured aerosol concentration to calculate the aerosol extinction in the cavity. There was no need to apply a correction for doubly charged particles (Wiedensohler, 1988) because only one size of particle was supplied to the DMA. The DMA was used to remove bead aggregates and surfactant particles that were also produced by the atomizer (Miles et al., 2010). A conservative uncertainty of $\pm 4 \%( \pm 15 \mathrm{~nm})$ in the size-selected particle diameter is assumed based on the reported sensitivity of the SMPS (Biskos et al., 2006) and the size distribution in the PSL standard. As can be seen in Fig. 8 for aerosol with $\mathrm{NO}_{2}$, and in Fig. 9 for aerosol with glyoxal and methyl glyoxal, the aerosol extinction retrieved from the change in the $\mathrm{O}_{4} \mathrm{SCD}$ by Eq. (9) agreed within error bars with the Mie theory calculations at $477 \mathrm{~nm}$ (Figs. $8 \mathrm{~b}$ and $9 \mathrm{~b}$ ) and $443 \mathrm{~nm}$ (Fig. 8c). The measurement of the aerosol extinction at two wavelengths allows us to interpolate the wavelength dependence of the aerosol 


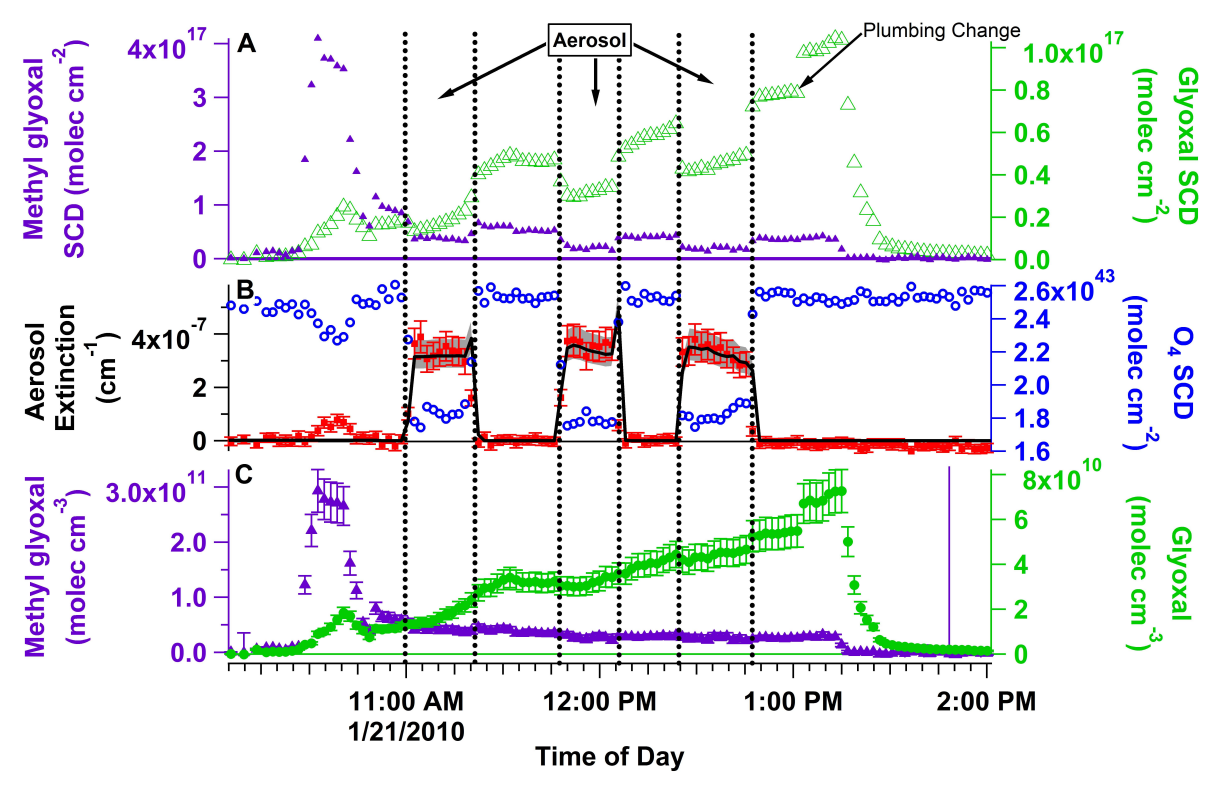

Fig. 9. Simultaneous retrieval of glyoxal, methyl glyoxal and aerosol extinction at one wavelength in closed cavity mode. (A) Slant column densities (SCD) of glyoxal (green open triangles) and methyl glyoxal (purple triangles). (B) $\mathrm{O}_{4} \mathrm{SCD}$ (blue circles), retrieved aerosol extinction from the change in the $\mathrm{O}_{4} \mathrm{SCD}$ (red squares) and the calculated aerosol extinction from Mie theory (solid line, gray area represents the uncertainty in aerosol sizing; peaks at the end of the first two aerosol periods are due to artifacts in the CPC counting). (C) Retrieved concentrations of glyoxal (green dots) and methyl glyoxal (purple triangles) corrected for path length by the retrieved aerosol extinction.

extinction for the $\mathrm{NO}_{2}$ experiment. The dynamic range over which aerosol extinction was varied is limited by the atomizer output, and needs to be regarded in relation to the aerosol free cavity loss. Indeed the lower value of aerosol extinction exceeds the extinction due to Rayleigh scattering in our cavity. The upper end value of aerosol extinction is the dominating extinction over the combined Rayleigh and mirror loss. Our experiments vary the overall extinction loss by a significant factor of 2.2, as illustrated in Fig. S1 in the Supplement.

For the glyoxal and methyl glyoxal experiment the known wavelength dependence of the aerosol extinction was used with the mirror reflectivity to retrieve the path length for the glyoxal and methyl glyoxal. The retrieved $\lambda^{-n}$ dependence $\left(\lambda^{-3.8 \pm 2.1}\right)$ of the extinction matches well with the dependence calculated from Mie theory $\left(\lambda^{-3}\right)$. The variability is still largely due to the measurement of the aerosol extinction at the water wavelength that is currently limited by the accuracy in the RH measurement. Alternative means to infer the wavelength dependence of aerosol extinction are provided by measuring a gas which absorbs over a broad wavelength range, e.g., $\mathrm{NO}_{2}$, at $477 \mathrm{~nm}$ (the $\mathrm{O}_{4}$ wavelength), and use the known wavelength dependence of that gas to derive the wavelength dependence of aerosol extinction. While $\mathrm{NO}_{2}$ can not always be relied on to be present in detectable amounts, oxygen and water are among the most abundant molecules in the lower atmosphere, and provide sufficient means to calibrate the wavelength dependence of aerosol extinction, and thus derive $L_{\text {eff }}$ as a function of wavelength.

\subsection{Open cavity detection of $\mathrm{NO}_{2}$, glyoxal and methyl glyoxal}

The inherent $\mathrm{O}_{4}$ path length calibration of our LED-CEDOAS instrument enables its use in open cavity mode. The concentrations of $\mathrm{NO}_{2}$, glyoxal and methyl glyoxal were measured simultaneously in laboratory air with the cavity operating in open cavity mode. Figure 10 shows the retrievals of these trace gases from spectra that were recorded in open cavity mode. The path length for glyoxal and methyl glyoxal were retrieved by using the $\mathrm{O}_{4}$ path to measure the $\mathrm{NO}_{2}$ concentration and then using the $\mathrm{NO}_{2}$ concentration and SCD in the glyoxal fit window to retrieve the path length for the desired trace gases as described above. Using the inherent path length calibration, the lab air between the mirrors was characterized to be composed of: $\mathrm{NO}_{2}$, methyl glyoxal and glyoxal of $2.47 \pm 0.07 \mathrm{ppbv}, 1.2 \pm 0.2 \mathrm{pbbv}$, and $274 \pm 14$ pptv respectively and an aerosol extinction measured from $\mathrm{O}_{4}$ of $4 \pm 3 \times 10^{-8} \mathrm{~cm}^{-1}$. This is to our knowledge the first inherently calibrated blue CEAS measurement in open air. 


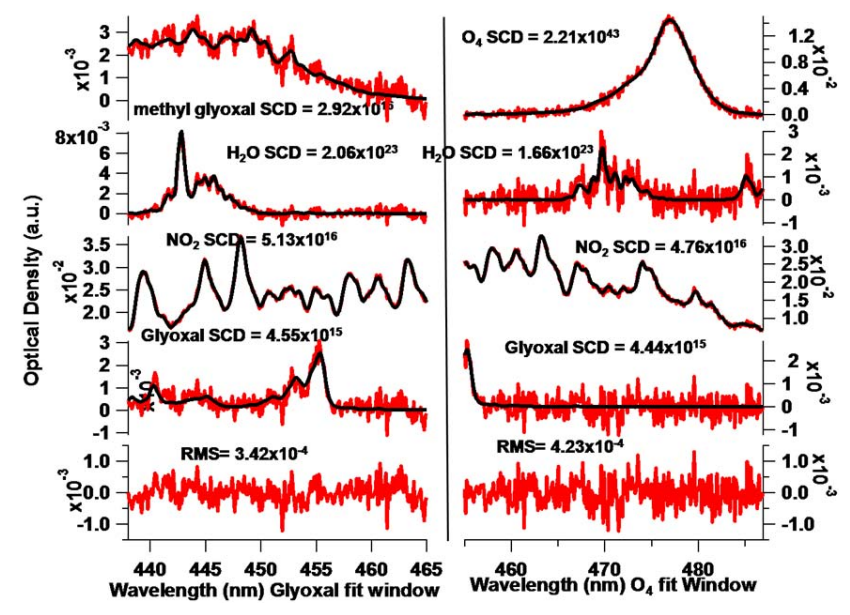

Fig. 10. Example retrievals using LED-CE-DOAS in open cavity mode: glyoxal (274 $\pm 14 \mathrm{pptv}), \mathrm{NO}_{2}(2.47 \pm 0.07 \mathrm{ppbv})$, methyl glyoxal $(1.2 \pm 0.2 \mathrm{ppbv})$, water and $\mathrm{O}_{4}$.

\section{Discussion}

\subsection{Normalization of blue CEAS instrument sensitivities}

Table 4 compares the instruments listed in Table 1 in terms of their sensitivities for a common integration time of $1 \mathrm{~min}$. Normalization is needed to account for different units, and also to compare the "detection sensitivity" of different instruments at a common confidence level. Values of RMS residuum noise in units of $\mathrm{cm}^{-1}$ (typical of most previous CEAS literature) were converted into the equivalent RMS noise (arbitrary units) by multiplying with $L_{\text {eff }}$, RMS equivalent noise in arbitrary units of "optical density" is listed at the 2- $\sigma$ confidence level. The normalized "detection sensitivity" (units of molec $\mathrm{cm}^{-3}$ ) was then calculated by dividing this 2- $\sigma$ RMS noise by the product of $\sigma$ (absolute retrievals; $\sigma^{\prime}$ for relative retrievals; units of $\mathrm{cm}^{2}$ molec ${ }^{-1}$ ) and $L_{\text {eff }}$ (units of $\mathrm{cm}$ ), see footnotes to Table 4 for values used for individual gases. Notably, this measure of instrument noise differs from that of the "fit error" that is often treated as equivalent to "detection sensitivity" in the BB-CEAS literature. For example, the $1-\sigma$ RMS residual noise of $3.75 \times 10^{-9} \mathrm{~cm}^{-1}$ reported by Ball and Jones (2009) corresponds to a 1-sigma fit error of 59 ppt $\mathrm{NO}_{2}$; this same $\mathrm{NO}_{2}$ concentration corresponds to an optical density of $4.6 \times 10^{-4}$, or ca. $0.3-\sigma$ on the RMS noise scale (compare Table 4). Likewise, glyoxal concentrations observed in Fig. 8 of Washenfelder et al. (2008) are negative to 5- $\sigma$ "fit error"; negative concentrations are non-physical, and are taken here to be marginally equivalent to "zero", which agrees well with the 2- $\sigma$ RMS noise equivalent detection sensitivity in Table 4. Our scaling is generally consistent with Stutz and Platt (1996), who found that the true error can be underestimated by up to a factor of 6 if equated to the standard least-squares fit error. Notably, Table 4 normalizes "detection sensitivity" to a common and conservative confidence level for the simple means of comparison between instruments; a similar calculation could equally be performed at another confidence level. Our choice of "normalized detection sensitivity" allows for reasonable "white noise" residuals to verify "by eye" the spectral proof of detection.

\subsection{LED and inherent path length calibration}

Ball et al. (2004) pioneered the use of LEDs with CEAS applications (see Sect. 1). At blue wavelengths, the $3 \mathrm{~W}$ Luxeon Royal blue used to be the strongest available LED; it had approximately half the intensity of a $450 \mathrm{~W}$ Xe-arc lamp (Kern et al., 2006). The optical output measured in Sect. 2.1.2 from the $5 \mathrm{~W}$ LEDengin LED, see Table 1, is about three times higher peak spectral intensity compared to that calculated for a $450 \mathrm{~W}$ Xe-arc lamp $(\varepsilon=0.15)$, and about 5-6 times higher than the $3 \mathrm{~W}$ Luxeon LEDs, see Fig. 3a.

Notably, the inherent path length calibration requires high $R$ mirrors and low photon shot-noise (strong light sources). The high $R$ mirrors reject valuable photons in a situation where the instrument noise is photon shot noise limited. The high intensity LEDengin makes up for some of these losses, and enables us to widen the wavelength window by avoiding the use of filters to suppress out of band light (detection of $\mathrm{O}_{4}$ at $477 \mathrm{~nm}$ ). The particular challenge with realizing inherent path length calibration at blue wavelengths is illustrated in Table 4, and consists in the need for accurate measurements of $\mathrm{O}_{4}$ and or water at ambient $\mathrm{O}_{2}$ partial pressures. Table 4 compares the normalized $\mathrm{O}_{4}$ detection sensitivity of different instruments (expressed as equivalent $\mathrm{O}_{2}$ partial pressure). Previous instruments detect $\mathrm{O}_{4}$ only in an oxygen enriched atmosphere, and leverage that $\mathrm{O}_{4}$ abundance scales with the square of the $\mathrm{O}_{2}$ partial pressure (collision induced absorption of two $\mathrm{O}_{2}$ molecules). Our $\mathrm{O}_{4}$ signal-to-noise ratio is $\sim 110$ times higher than $\mathrm{Wu}$ et al. (2009) (using the same $\mathrm{O}_{4}$ band) and $\sim 150$ times that in Langdridge et al. (2006). Our detection sensitivity is sufficient to detect a $1 \%$ change in the $\mathrm{O}_{4}$ SCD under STP conditions in air, or $0.1 \%$ change in the ambient $\mathrm{O}_{2}$ partial pressure, see Table 3. The combination of three factors enables this accuracy: (1) high $R$ mirrors (longer $L_{\text {eff }}$ ), (2) low RMS noise, and (3) use of the stronger $\mathrm{O}_{4}$ band near $477 \mathrm{~nm}$. The instrument sensitivity is improved also for other gases, i.e., by at least a factor of 3.3 $\left(\mathrm{NO}_{2}\right), 7$ (CHOCHO), 450 (IO), and 10 (water), see Table 4.

Other LED advantages help to make the blue spectral range more accessible for DOAS applications, but are not unique to the LEDengin. These consist in an unstructured LED emission spectrum that is rather constant in time, the use of standard laboratory power supplies, reduction in instrument size, increased instrument reliability, longer lifetime and better cost and power effectiveness of the light source (compared to Xe-arc lamps). 
Table 4. Normalization and comparison of detection limits for trace gases measured with blue CEAS instruments.

\begin{tabular}{|c|c|c|c|c|c|}
\hline Trace Gas & $\begin{array}{l}L_{\text {eff }} \\
\left(\mathrm{km}^{\mathrm{a}}\right)\end{array}$ & $\begin{array}{l}\text { 1- } \sigma \text { RMS } \\
\text { (reported units) }\end{array}$ & $\begin{array}{l}2-\sigma \mathrm{RMS} \\
\left(\times 10^{-3} \text { a.u. }\right)\end{array}$ & $\begin{array}{l}\text { Normalized 2- } \sigma \\
\text { Detection Limit } \\
(\mathrm{pptv})^{\mathrm{b}} \text { in } 1 \text { min }\end{array}$ & Reference \\
\hline \multirow[t]{5}{*}{$\mathrm{NO}_{2}$} & 4.5 & $2.9 \times 10^{-9} \mathrm{~cm}^{-1}$ & 2.6 & 325 & Langridge et al. (2006) \\
\hline & 17.9 & $20 \mathrm{pptv}^{\mathrm{c}}$ & $\sim 4^{\mathrm{d}}$ & $100^{\mathrm{d}}$ & Washenfelder et al. (2008) \\
\hline & 4.5 & $3.75 \times 10^{-9} \mathrm{~cm}^{-1}$ & 3.3 & 420 & Ball and Jones (2009) \\
\hline & 0.3 & $1.72 \times 10^{-8} \mathrm{~cm}^{-1}$ & 1.0 & $3400^{b}$ & Wu et al. (2009) \\
\hline & 13 & $2 \times 10^{-4}$ & 0.4 & 30 & This work \\
\hline \multirow[t]{2}{*}{$\mathrm{CHOCHO}$} & 17.9 & 29 pptv $^{\mathrm{c}}$ & $\sim 4^{\mathrm{d}}$ & $150^{\mathrm{d}}$ & Washenfelder et al. (2008) \\
\hline & 13 & $2 \times 10^{-4}$ & 0.4 & 19 & This work \\
\hline $\mathrm{CH}_{3} \mathrm{COCHO}$ & 13 & $2 \times 10^{-4}$ & 0.4 & 170 & This work \\
\hline \multirow[t]{3}{*}{ IO } & 0.68 & $7.9 \times 10^{-8} \mathrm{~cm}^{-1}$ & 10.7 & 315 & Vaughan et al. (2008) \\
\hline & 3.2 & $1.3 \times 10^{-7} \mathrm{~cm}^{-1}$ & 83 & 520 & Vaughan et al. (2008) \\
\hline & 11 & $2 \times 10^{-4}$ & 0.4 & 0.7 & This work \\
\hline \multirow[t]{2}{*}{$\mathrm{H}_{2} \mathrm{O}$} & 15 & 0.84 ppthv $^{\mathrm{c}}$ & $\sim 4^{\mathrm{d}}$ & $0.3 \% \mathrm{~d}$ & Washenfelder et al. (2008) \\
\hline & 13 & $2 \times 10^{-4}$ & 0.4 & $0.028 \%$ & This work \\
\hline \multirow[t]{3}{*}{$\mathrm{O}_{4}$} & 4.5 & $2.9 \times 10^{-9} \mathrm{~cm}^{-1}$ & 2.6 & $43 \% \mathrm{e}$ & Langridge et al. (2006) \\
\hline & 0.3 & $1.72 \times 10^{-8} \mathrm{~cm}^{-1}$ & 1.0 & $35 \% \mathrm{e}$ & Wu et al. (2009) \\
\hline & 14 & $3.5 \times 10^{-4}$ & 0.7 & $3.5 \% \mathrm{e}^{\mathrm{e}}$ & This work \\
\hline
\end{tabular}

${ }^{\text {a }}$ Calculated from Eq. (1) for Rayleigh case in air, density of $2.5 \times 10^{19} \mathrm{molec}^{-3}$.

b Normalized to reflect the 2- $\sigma$ RMS confidence level in "optical density" equivalent units; calculated by dividing 2- $\sigma$ RMS residual noise (column to the left) by $L_{\text {eff }}$, and the cross section; for $\mathrm{NO}_{2}$ the absolute cross-section is used for BB-CEAS retrievals $\left(\sigma_{\mathrm{NO}_{2}}=7 \times 10^{-19} \mathrm{~cm}^{2} \mathrm{molec}^{-1}\right)$, and $\sigma^{\prime} \mathrm{NO}_{2}=4 \times 10^{-19} \mathrm{~cm}^{2}$ molec ${ }^{-1}$ is used for DOAS retrievals (and $4 \times 10^{-19} \mathrm{~cm}^{2} \mathrm{molec}^{-1}$ for $480 \mathrm{~nm}$ for Wu et al., 2009), this gives a favorable estimate for BB-CEAS (see Sect. 4.1); other gases are converted based on the following values: $\sigma_{\mathrm{IO}}^{\prime}=2 \times 10^{-17} \mathrm{~cm}^{2} \mathrm{molec}^{-1}, \sigma_{\mathrm{O}_{4}}(477 \mathrm{~nm})=6.5 \times 10^{-46} \mathrm{~cm}^{5} \mathrm{molec}^{-2}, \sigma_{\mathrm{O}_{4}}(446 \mathrm{~nm})=5 \times 10^{-47} \mathrm{~cm}^{5} \mathrm{molec}^{-2}, \sigma_{\mathrm{CHOCHO}}=6.5 \times 10^{-19} \mathrm{~cm}^{2} \mathrm{molec}^{-1}$, $\sigma_{\mathrm{H} 2 \mathrm{O}}=4.3 \times 10^{-26} \mathrm{~cm}^{2} \mathrm{molec}^{-1}$.

${ }^{c}$ Reported $1 \sigma$ fit error interpreted as equivalent to measurement precision (see Sect. 4.1), ppthv= permille volume mixing ratio.

d No statistical residuals are reported in this paper; the detection limits are estimated from the distribution around zero in Fig. 8 of Washenfelder et al. (2008), see text for details.

${ }^{\text {e }}$ Calculated as equivalent $\mathrm{O}_{2}$ partial pressure in air at STP.

\subsection{Benefits of DOAS retrievals}

DOAS retrievals are inherently insensitive to lamp drift. Once the retrieval method is established, such relative retrievals provide a software solution to the problem of lamp drift. Since CE-DOAS only relies on a relative intensity distribution of the lamp spectrum, the frequency at which the lamp needs to be characterized is greatly reduced. For example, we can run our instrument over several days with a single lamp spectrum, without the need to reduce the duty cycle to characterize the lamp intensity and/or cavity transmission. The strong LED, coupled with the reduced need for calibrations makes time and photons available to reduce photon shot noise, improve the signal-to-noise ratio, and achieve lower detection limits without sacrificing the ability to demonstrate "control" over cavity transmission. While the measurement of $\mathrm{O}_{4}$ and water are not proprietary of relative retrievals, the ability to detect these gases relies exclusively on the concept of "differential" absorption for which DOAS retrievals are optimized.
Notably, for comparable 1-min integration time the RMS noise in our DOAS retrieval is about 2.5 to 10 times lower than previous CEAS applications at blue wavelengths, more in instances (see Table 4). We characterized the light intensity drift in our instrument at about $4 \times 10^{-10} \mathrm{~cm}^{-1}$ over the course of several hours. With $L_{\text {eff }}$ equal $1.3 \times 10^{6} \mathrm{~cm}$ this corresponds to $\sim 5 \times 10^{-4}$ optical density. Notably, our RMS residual noise from relative retrievals is below this threshold already at 1-min integration time, and decreases further with no apparent deviation from photon-noise statistics for longer averaging times, compare Fig. 4. This presents a direct demonstration that the benefit of lower RMS can at least partly be attributed to DOAS retrievals. Previous CEAS applications listed in Table 4 used absolute retrievals (Ball et al., 2004; Fiedler et al., 2003; O'Keefe et al., 1998) that require knowledge of $I_{0}$, the light intensity in absence of absorbers. From Table 4 it appears that absolute retrievals are limited at RMS $\sim 10^{-3}$, higher in instances. The higher RMS values tend to correspond to instruments that use Xe-arc 
lamps; instruments that employ LEDs tend to give better RMS. The study of Wu et al. (2009) employed very low $R$ mirrors (two orders of magnitude lower than this work) and despite abundant light their noise level is about 2.5 times the RMS derived in this work; the stability of their LED did not allow for RMS to improve beyond $\sim 50$ to $100 \mathrm{~s}$ averaging time. State-of-the-art CEAS applications currently dedicate separate hardware to measuring fluctuations in $I_{0}$ by observing "single-traverse" out-of-band light (Washenfelder et al., 2008; Chen and Venables, 2010). The need to characterize and correct for drift in $I_{0}$ adds to the hardware cost, increases shot-noise in the measurement of interest by using a portion of the available photons to characterize $I_{0}$, and adds an uncertainty that can limit the minimal extinction which can be quantified; the uncertainty of the separate $I_{0}$ measurement needs to be propagated into the final error of absolute retrievals. DOAS retrievals eliminate such hardware needs and potential for error.

DOAS retrievals do not have any particular benefit over absolute retrievals to separate further between broad band extinction from aerosols, changes in $R$ or cavity alignment, or atmospheric turbulence; in either retrieval the decoupling of aerosol extinction relies on engineering solutions of the cavity and air supply. Notably, in an unknown mixture of gases any retrieval techniques relies exclusively on differential absorption features to distinguish between the individual gases that contribute to the total extinction from the cavity. CEAS "selectivity", or the ability to give spectral proof for unambiguous detection of a specific gas, relies on comparing the differential "signal" (relative retrievals: arbitrary units typical of "optical density"; absolute retrievals: units of $\mathrm{cm}^{-1}$ ) in relation to the RMS noise; the broad band extinction from $\sigma_{\mathrm{b}}($ Eq. 4 ) is convoluted with aerosol extinction, changes in $R$ or cavity alignment, and/or atmospheric turbulence, and - in the case of BB-CEAS retrievals also drift in $I_{0}$. Conversely the benefit of $\sigma_{\mathrm{b}}$ towards the "sensitivity", or ability to quantify the concentration, becomes ill defined. For gases like glyoxal and IO, where $\sigma$ and $\sigma^{\prime}$ are near identical, there is no benefit in absolute retrievals.

Finally, the fit residual carries valuable information to "alert" of the potential for systematic bias (Stutz and Platt, 2008): limitations in hardware, and/or the incomplete accounting of absorbers can create systematic residual structure and impose a cap on the attainable detection limit due to spectral cross-correlations with overlapping features between the residual and other absorbers. Notably, DOAS retrievals maintain "units" that facilitate a straightforward comparison with theoretical RMS noise (i.e., photon-shotnoise, see Fig. 4, Sect. 2.1.4). The attainable RMS of other DOAS applications continues to decrease as our understanding of hardware limitations that cause deviations from photon-shot noise statistics at very low noise levels continues to improve (Coburn et al., 2010; Volkamer et al., 2009a): $1-\sigma$ RMS $\sim 6 \times 10^{-6}$ has been realized in laboratory applications, and $\sim 1 \times 10^{-4}$ can now routinely be achieved (see Fig. 4, and also Table 1 in Coburn et al., 2010). Such DOAS hardware is transferrable to LED-CE-DOAS applications. Future improvements in RMS will also depend on the availability of improved laboratory cross-section data.

\section{Conclusions}

We demonstrate inherently calibrated CEAS measurements at blue wavelengths, and measured glyoxal, methyl glyoxal, $\mathrm{NO}_{2}$, water and aerosol extinction at $443 \mathrm{~nm}$ and $477 \mathrm{~nm}$ in open cavity mode. The open cavity mode eliminates the need for sampling lines, and is particularly useful for measurements of reactive gases and iodine oxide radicals that can get lost in sampling lines.

- A strong LED coupled with high $R$ mirrors and DOAS retrievals enables low detections limits, while maintaining the ability to demonstrate on-line "control" over cavity transmission. The method is based on excellent signal to noise measurements of $\mathrm{O}_{4}$ at atmospheric conditions as part of each spectrum. The path length calculation only requires a pressure reading as input. Similarly, measurements of the $\mathrm{H}_{2} \mathrm{O}$ in combination with relative humidity and temperature are used.

- To our knowledge ours is the first retrieval of aerosol extinction by a CEAS instrument that has been verified quantitatively using Mie theory. Two methods are presented to characterize the wavelength dependence of aerosol extinction as pre-requisite for path length calculations in open cavity mode.

- Such control over cavity transmission enables the use of CEAS cavities as direct alternative to traditional multi-reflection cells, for which the number of reflections is geometrically defined, and constant. The maximum number of passes in our cavity $\left(\sim 1.7 \times 10^{4}\right)$ compares favorably to White-cells (16 to 144), Herriott-cells ( 100), and astigmatic-type multi-reflection cells (up to 182). The increased photon path length leads to an accordingly better sensitivity.

- DOAS retrievals provide a software solution to the problem of lamp drift, and lowers the attainable RMS noise from CEAS measurements. The sensitivity of our LEDCE-DOAS is suitable for atmospheric measurements of glyoxal, iodine oxide, nitrogen dioxide and aerosol extinction in polluted and pristine air, and sufficient to detect methyl glyoxal directly under simulated atmospheric conditions.

\section{Supplementary material related to this article is available online at: \\ http://www.atmos-meas-tech.net/3/1797/2010/ amt-3-1797-2010-supplement.pdf.}


Acknowledgements. This work was supported by the National Science Foundation CAREER award ATM-847793, CU start-up funds and NASA Earth and Space Science Fellowship 09-EARTH09F-88. The authors like to thank Jose Luis Jimenez, Steve Brown, Rebecca Washenfelder, and Christa Hasenkopf for use of calibration equipment, and helpful discussions, Barbara Dix and Eleanor Waxman provided guidance on the WinDOAS software package, and comments on the manuscript.

Edited by: J. Stutz

\section{References}

Ball, S. M. and Jones, R. L.: Broadband Cavity Ring-down, in: Cavity Ring-Down Spectroscopy: Techniques and Applications, edited by: Berden, G. and Englen, R., John Wiley and Sons LTD, Chichester, 89-111, 2009.

Ball, S. M., Langridge, J. M., and Jones, R. L.: Broadband cavity enhanced absorption spectroscopy using light emitting diodes, Chem. Phys. Lett., 398, 68-74, 2004.

Ball, S. M., Hollingsworth, A. M., Humbles, J., Leblanc, C., Potin, P., and McFiggans, G.: Spectroscopic studies of molecular iodine emitted into the gas phase by seaweed, Atmos. Chem. Phys., 10, 6237-6254, doi:10.5194/acp-10-6237-2010, 2010.

Betterton, E. A. and Hoffmann, M. R.: Henry's law constants of some environmentally important aldehydes, Environ. Sci. Technol., 22, 1415-1418, 1988.

Biskos, G., Paulsen, D., Russell, L. M., Buseck, P. R., and Martin, S. T.: Prompt deliquescence and efflorescence of aerosol nanoparticles, Atmos. Chem. Phys., 6, 4633-4642, doi:10.5194/acp-64633-2006, 2006.

Bloss, C., Wagner, V., Bonzanini, A., Jenkin, M. E., Wirtz, K., Martin-Reviejo, M., and Pilling, M. J.: Evaluation of detailed aromatic mechanisms (MCMv3 and MCMv3.1) against environmental chamber data, Atmos. Chem. Phys., 5, 623-639, doi:10.5194/acp-5-623-2005, 2005.

Bodhaine, B. A., Wood, N. B., Dutton, E. G., and Slusser, J. R.: On Rayleigh Optical Depth Calculations, J. Atmos. Ocean. Tech., 16, 1854-1861, 1999.

Brown, S. S.: Absorption spectroscopy in high-finesse cavities for atmospheric studies, Chem. Rev., 103, 5219-5238, 2003.

Chen, J. and Venables, D. S.: A broadband optical cavity spectrometer for measuring weak near-ultraviolet absorption spectra of gases, Atmos. Meas. Tech. Discuss., 3, 4571-4602, doi:10.5194/amtd-3-4571-2010, 2010.

Coburn, S., Dix, B., Sinreich, R., and Volkamer, R.: Development and Characterization of the CU Ground MAX-DOAS Instrument: lowering RMS noise and first measurements of BrO, IO, and CHOCHO near Pensacola, FL, Atmos. Meas. Tech. Discuss., submitted, 2010.

Dibble, T. S.: Intramolecular Hydrogen Bonding and Double HAtom Transfer in Peroxy and Alkoxy Radicals from Isoprene, J. Phys. Chem. A, 108, 2199-2207, 2004a.

Dibble, T. S.: Prompt Chemistry of Alkenoxy Radical Products of the Double H-Atom Transfer of Alkoxy Radicals from Isoprene, J. Phys. Chem. A, 108, 2208-2215, 2004b.
Dixneuf, S., Ruth, A. A., Vaughan, S., Varma, R. M., and Orphal, J.: The time dependence of molecular iodine emission from Laminaria digitata, Atmos. Chem. Phys., 9, 823-829, doi:10.5194/acp-9-823-2009, 2009.

Ervens, B. and Volkamer, R.: Glyoxal processing by aerosol multiphase chemistry: towards a kinetic modeling framework of secondary organic aerosol formation in aqueous particles, Atmos. Chem. Phys., 10, 8219-8244, doi:10.5194/acp-10-8219-2010, 2010.

Fayt, C. and Van Roosendael, M.: WinDOAS User Manual, 2001.

Fiedler, S. E., Hese, A., and Ruth, A. A.: Incoherent broad-band cavity-enhanced absorption spectroscopy, Chem. Phys. Lett., 371, 284-294, 2003.

Fiedler, S. E., Hese, A., and Heitmann, U.: Influence of the cavity parameters on the output intensity in incoherent broadband cavity-enhanced absorption spectroscopy, Rev. Sci. Instrum., 78, 073104, doi:10.1063/1.2752608, 2007.

Fu, T. M., Jacob, D. J., Wittrock, F., Burrows, J. P., Vrekoussis, M., and Henze, D. K.: Global budgets of atmospheric glyoxal and methylglyoxal, and implications for formation of secondary organic aerosols, J. Geophys. Res., 113, D15303, doi:10.1029/2007JD009505, 2008.

Galloway, M. M., Chhabra, P. S., Chan, A. W. H., Surratt, J. D., Flagan, R. C., Seinfeld, J. H., and Keutsch, F. N.: Glyoxal uptake on ammonium sulphate seed aerosol: reaction products and reversibility of uptake under dark and irradiated conditions, Atmos. Chem. Phys., 9, 3331-3345, doi:10.5194/acp-9-3331-2009, 2009.

Gherman, T., Venables, D. S., Vaughan, S., Orphal, J., and Ruth, A. A.: Incoherent broadband cavity-enhanced absorption spectroscopy in the near-ultraviolet: Application to $\mathrm{HONO}$ and $\mathrm{NO}_{2}$, Environ. Sci. Technol., 42, 890-895, 2008.

Gomez Martin, J. C. G., Spietz, P., and Burrows, J. P.: Kinetic and mechanistic studies of the I-2/O-3 photochemistry, J. Phys. Chem. A, 111, 306-320, 2007.

Hastings, W. P., Koehler, C. A., Bailey, E. L., and De Haan, D. O.: Secondary organic aerosol formation by glyoxal hydration and oligomer formation: Humidity effects and equilibrium shifts during analysis, Environ. Sci. Technol., 39, 8728-8735, 2005.

Hermans, C.: Measurement of absorption cross sections and spectroscopic molecular parameters: $\mathrm{O}_{2}$ and its collisonal induced absorption: http://www.aeronomie.be/spectrolab/o2. htm4-9-20104-26-3010 last access: 16 December, 2010.

Herriott, D. R. and Schulte, H. J.: Folded Optical Delay Lines, Appl. Optics, 4, 883-889, 1965.

Hönninger, G.: Referenzspektren reaktiver Halogenverbindungen für DOAS-Messungen, 1999.

Huisman, A. J., Hottle, J. R., Coens, K. L., DiGangi, J. P., Galloway, M. M., Kammrath, A., and Keutsch, F. N.: Laser-Induced Phosphorescence for the in Situ Detection of Glyoxal at Part per Trillion Mixing Ratios, Anal. Chem., 80, 5884-5891, 2008.

Ip, H. S. S., Huang, X. H. H., and Yu, J. Z.: Effective Henry's law constants of glyoxal, glyoxylic acid, and glycolic acid, Geophys. Res. Lett., 36, L01802, doi:10.1029/2008GL036212, 2009.

Jang, M., Czoschke, N. M., Lee, S., and Kamens, R. M.: Heterogeneous Atmospheric Aerosol Production by Acid-Catalyzed Particle-Phase Reactions, Science, 298, 814-817, 2002. 
Kern, C., Trick, S., Rippel, B., and Platt, U.: Applicability of lightemitting diodes as light sources for active differential optical absorption spectroscopy measurements, Appl. Optics, 45, 20772088, 2006

Kurosu, T., Chance, K., and Volkamer, R.: Global measurements of $\mathrm{OClO}, \mathrm{BrO}, \mathrm{HCHO}$, and $\mathrm{CHO}-\mathrm{CHO}$ from the Ozone Monitoring Instruments on EOS Aura, EOS Trans. EGU, 86, Fall Meet. Suppl. Abstract A54B-01, 2005.

Langridge, J. M., Ball, S. M., and Jones, R. L.: A compact broadband cavity enhanced absorption spectrometer for detection of atmospheric $\mathrm{NO}_{2}$ using light emitting diodes, Analyst, 131, 916922, 2006

Langridge, J. M., Ball, S. M., Shillings, A. J. L., and Jones, R. L.: A broadband absorption spectrometer using light emitting diodes for ultrasensitive, in situ trace gas detection, Rev. Sci. Instrum., 79, 123110, doi:10.1063/1.3046282, 2008a.

Langridge, J. M., Laurila, T., Watt, R. S., Jones, R. L., Kaminski, C. F., and Hult, J.: Cavity enhanced absorption spectroscopy of multiple trace gas species using a supercontinuum radiation source, Opt. Express, 16, 10178-10188, 2008b.

Liggio, J., Li, S. M., and McLaren, R.: Reactive uptake of glyoxal by particulate matter, J. Geophys. Res., 110, D10304, doi:10.1029/2004JD005113, 2005.

McManus, J. B., Kebabian, P. L., and Zahniser, M. S.: Astigmatic mirror multipass absorption cells for long-path-length spectroscopy, Appl. Optics, 34, 3336-3348, 1995.

Meinen, J., Thieser, J., Platt, U., and Leisner, T.: Technical Note: Using a high finesse optical resonator to provide a long light path for differential optical absorption spectroscopy: CE-DOAS, Atmos. Chem. Phys., 10, 3901-3914, doi:10.5194/acp-10-39012010, 2010.

Meller, R., Raber, W., Crowley, J. N., Jenkin, M. E., and Moortgat, G. K.: The UV-visible absorption spectrum of methylglyoxal, J. Photoch. Photobio. A, 62, 163-171, 1991.

Miles, R. E. H., Rudic, S., Orr-Ewing, A. J., and Reid, J. P.: Measurements of the wavelength dependent extinction of aerosols by cavity ring down spectroscopy, Phys. Chem. Chem. Phys., 12, 3914-3920, 2010.

Myriokefalitakis, S., Vrekoussis, M., Tsigaridis, K., Wittrock, F., Richter, A., Brühl, C., Volkamer, R., Burrows, J. P., and Kanakidou, M.: The influence of natural and anthropogenic secondary sources on the glyoxal global distribution, Atmos. Chem. Phys., 8, 4965-4981, doi:10.5194/acp-8-4965-2008, 2008.

O'Keefe, A.: Integrated cavity output analysis of weak absorbers, Chem. Pys. Lett., 293, 331-336, 1998.

O'Keefe, A. and Deacon, D. A. G.: Cavity Ring-Down Optical Spectrometer for Absorption-Measurements Using Pulsed Laser Sources, Rev. Sci. Instrum., 59, 2544-2551, 1988.

Orphal, J. and Ruth, A. A.: High-resolution Fourier-transform cavity-enhanced absorption spectroscopy in the near-infrared using an incoherent broad-band light source, Opt. Express, 16, 19232-19243, 2008.

Platt, U. and Stutz, J.: Differential optical absorption spectroscopy: principles and applications, 1, Springer Verlag, Berlin, 2008.

Platt, U., Meinen, J., Pöhler, D., and Leisner, T.: Broadband Cavity Enhanced Differential Optical Absorption Spectroscopy (CEDOAS) - applicability and corrections, Atmos. Meas. Tech., 2, 713-723, doi:10.5194/amt-2-713-2009, 2009.
Pope, C. A. and Dockery, D. W.: Health effects of fine particulate air pollution: Lines that connect, J. Air Waste Manage., 56, 709$742,2006$.

Rothman, L. S., Gordon, I. E., Barbe, A., Benner, D. C., Bernath, P. F., Birk, M., Boudon, V., Brown, L. R., Campargue, A., Champion, J. P., Chance, K., Coudert, L. H., Dana, V., Devi, V. M., Fally, S., Flaud, J. M., Gamache, R. R., Goldman, A., Jacquemart, D., Kleiner, I., Lacome, N., Lafferty, W. J., Mandin, J. Y., Massie, S. T., Mikhailenko, S. N., Miller, C. E., Moazzen-Ahmadi, N., Naumenko, O. V., Nikitin, A. V., Orphal, J., Perevalov, V. I., Perrin, A., Predoi-Cross, A., Rinsland, C. P., Rotger, M., Simeckov, M., Smith, M. A. H., Sung, K., Tashkun, S. A., Tennyson, J., Toth, R. A., Vandaele, A. C., and Vander Auwera, J.: The HITRAN 2008 molecular spectroscopic database, J. Quant. Spectrosc. Ra., 110, 533-572, 2006.

Schuster, G., Labazan, I., and Crowley, J. N.: A cavity ring down/cavity enhanced absorption device for measurement of ambient $\mathrm{NO}_{3}$ and $\mathrm{N}_{2} \mathrm{O}_{5}$, Atmos. Meas. Tech., 2, 1-13, doi:10.5194/amt-2-1-2009, 2009.

Sihler, H., Kern, C., Pohler, D., and Platt, U.: Applying lightemitting diodes with narrowband emission features in differential spectroscopy, Opt. Lett., 34, 3716-3718, 2009.

Sinreich, R., Volkamer, R., Filsinger, F., Frieß, U., Kern, C., Platt, U., Sebastián, O., and Wagner, T.: MAX-DOAS detection of glyoxal during ICARTT 2004, Atmos. Chem. Phys., 7, 1293-1303, doi:10.5194/acp-7-1293-2007, 2007.

Sneep, M. and Ubachs, W.: Direct measurement of the Rayleigh scattering cross section in various gases, J. Quant. Spectrosc. Ra. 92, 293-310, 2005.

Stavrakou, T., Müller, J.-F., De Smedt, I., Van Roozendael, M., Kanakidou, M., Vrekoussis, M., Wittrock, F., Richter, A., and Burrows, J. P.: The continental source of glyoxal estimated by the synergistic use of spaceborne measurements and inverse modelling, Atmos. Chem. Phys., 9, 8431-8446, doi:10.5194/acp-9-8431-2009, 2009.

Stutz, J. and Platt, U.: Numerical analysis and estimation of the statistical error of differential optical absorption spectroscopy measurements with least-squares methods, Appl. Optics, 35, 60416053, 1996.

Tan, Y., Perri, M. J., Seitzinger, S. P., and Turpin, B. J.: Effects of Precursor Concentration and Acidic Sulfate in Aqueous Glyoxal $\mathrm{OH}$ Radical Oxidation and Implications for Secondary Organic Aerosol, Environ. Sci. Technol., 43, 8105-8112, 2009.

Taraborrelli, D., Lawrence, M. G., Butler, T. M., Sander, R., and Lelieveld, J.: Mainz Isoprene Mechanism 2 (MIM2): an isoprene oxidation mechanism for regional and global atmospheric modelling, Atmos. Chem. Phys., 9, 2751-2777, doi:10.5194/acp-92751-2009, 2009.

Triki, M., Cermak, P., Mejean, G., and Romanini, D.: Cavityenhanced absorption spectroscopy with a red LED source for $\mathrm{NO}_{\mathrm{x}}$ trace analysis, Appl. Phys. B, 91, 195-201, 2008.

Vandaele, A. C., Hermans, C., Fally, S., Carleer, M., Colin, R., Mérienne, M. F., Jenouvrier, A., and Coquart, B.: Highresolution Fourier transform measurement of the $\mathrm{NO}_{2}$ visible and near-infrared absorption cross sections: Temperature and pressure effects, J. Geophys. Res., 107, 4348, 2002. 
Varma, R. M., Venables, D. S., Ruth, A. A., Heitmann, U., Schlosser, E., and Dixneuf, S.: Long optical cavities for openpath monitoring of atmospheric trace gases and aerosol extinction, Appl. Optics, 48, B159-B171, 2009.

Vaughan, S., Gherman, T., Ruth, A. A., and Orphal, J.: Incoherent broad-band cavity-enhanced absorption spectroscopy of the marine boundary layer species I-2, IO and OIO, Phys. Chem. Chem. Phys., 10, 4471-4477, 2008.

Venables, D. S., Gherman, T., Orphal, J., Wenger, J. C., and Ruth, A. A.: High sensitivity in situ monitoring of $\mathrm{NO}_{3}$ in an atmospheric simulation chamber using incoherent broadband cavityenhanced absorption spectroscopy, Environ. Sci. Technol., 40, 6758-6763, 2006.

Villalobos-Pietrini, R., Hernandez-Mena, L., Amador-Munoz, O., Munive-Colin, Z., Bravo-Cabrera, J. L., Gómez-Arroyo, S., Frias-Villegas, A., Waliszewski, S., Ramirez-Pulido, J., and Ortiz-Muniz, R.: Biodirected mutagenic chemical assay of $\mathrm{PM}_{10}$ extractable organic matter in Southwest Mexico City, Mutat. Res./Gen. Toxicol. Environ. Mutag., 634, 192-204, 2007.

Volkamer, R., Etzkorn, T., Geyer, A., and Platt, U.: Correction of the oxygen interference with UV spectroscopic (DOAS) measurements of monocyclic aromatic hydrocarbons in the atmosphere, Atmos. Environ., 32, 3731-3747, 1998.

Volkamer, R., Barnes, I., Platt, U., Molina, L. T., and Molina, M. J.: Remote Sensing of Glyoxal by Differential Optical Absorption Spectroscopy (DOAS): Advancements in Simulation Chamber and Field Experiments, in: Environmental Simulation Chambers: Application to Atmospheric Chemical Processes, edited by: Rudzinki, K. and Barnes, I., NATO Sci. Ser., IV Earth Environ. Sci. vol. 62, Kluwer Acad., Dortrecht, The Netherlands, 129142, 2005a.

Volkamer, R., Molina, L. T., Molina, M. J., Shirley, T., and Brune, W. H.: DOAS measurement of glyoxal as an indicator for fast VOC chemistry in urban air, Geophys. Res. Lett., 32, L08806, doi:10.1029/2005GL022616, 2005b.

Volkamer, R., Spietz, P., Burrows, J., and Platt, U.: High-resolution absorption cross-section of glyoxal in the UV-vis and IR spectral ranges, J. Photoch. Photobio. A, 172, 35-46, $2005 \mathrm{c}$.

Volkamer, R., San Martini, F., Molina, L. T., Salcedo, D., Jimenez, J. L., and Molina, M. J.: A missing sink for gas-phase glyoxal in Mexico City: Formation of secondary organic aerosol, Geophys. Res. Lett., 34, L19807, doi:10.1029/2007GL030752, 2007.
Volkamer, R., Coburn, S., Dix, B., and Sinreich, R.: MAX-DOAS observations from ground, ship, and research aircraft: maximizing signal-to-noise to measure "weak" absorbers, SPIE Proceedings "Ultraviolet and Visible Ground- and Space-based Measurements, Trace Gases, Aerosols and Effects", San Diego, 2-9 August 2009, paper 7264-4, doi:10.1117/12.826792, 2009a.

Volkamer, R., Ziemann, P. J., and Molina, M. J.: Secondary Organic Aerosol Formation from Acetylene $\left(\mathrm{C}_{2} \mathrm{H}_{2}\right)$ : seed effect on $\mathrm{SOA}$ yields due to organic photochemistry in the aerosol aqueous phase, Atmos. Chem. Phys., 9, 1907-1928, doi:10.5194/acp9-1907-2009, 2009b.

Volkamer, R., Coburn, S., Dix, B., and Sinreich, R.: The Eastern Pacific Ocean is a source for short lived trace gases: Glyoxal and Iodine Oxide, Clivar Exchanges April 2010, 15(2), No. 52, 30-33, 2010.

Vrekoussis, M., Wittrock, F., Richter, A., and Burrows, J. P.: Temporal and spatial variability of glyoxal as observed from space, Atmos. Chem. Phys., 9, 4485-4504, doi:10.5194/acp-9-44852009, 2009.

Washenfelder, R. A., Langford, A. O., Fuchs, H., and Brown, S. S.: Measurement of glyoxal using an incoherent broadband cavity enhanced absorption spectrometer, Atmos. Chem. Phys., 8, 7779-7793, doi:10.5194/acp-8-7779-2008, 2008.

White, J. U.: Long Optical Paths of Large Aperture, J. Opt. Soc. Am., 32, 285-288, 1942.

Wiedensohler, A.: An approximation of the bipolar charge distribution for particles in the submicron size range, J. Aerosol Sci., 19, 387-389, 1988.

Wittrock, F., Richter, A., Oetjen, H., Burrows, J. P., Kanakidou, M., Myriokefalitakis, S., Volkamer, R., Beirle, S., Platt, U., and Wagner, T.: Simultaneous global observations of glyoxal and formaldehyde from space, Geophys. Res. Lett., 33, 123110 , doi:10.1063/1.3046282, 2006.

Wu, T., Zhao, W., Chen, W., Zhang, W., and Gao, X.: Incoherent broadband cavity enhanced absorption spectroscopy for in situ measurements of $\mathrm{NO}_{2}$ with a blue light emitting diode, Appl. Phys. B, 94, 85-94, 2009.

Yu, J., Jeffries, H. E., and Sexton, K. G.: Atmospheric photooxidation of alkylbenzenes - I. Carbonyl product analyses, Atmos. Environ., 31, 2261-2280, 1997. 